\title{
New Laonice species (Polychaeta: Spionidae) from western and northern Austra- lia
}

\author{
ELIZABETH GREAVES ${ }^{1}$, KARIN MEIßNER $^{2} \&$ ROBIN WILSON ${ }^{3}$ \\ ${ }^{\text {I} S c i e n c e s ~ D e p a r t m e n t, ~ M u s e u m ~ V i c t o r i a, ~ G P O ~ B o x ~ 666, ~ M e l b o u r n e, ~ V i c t o r i a ~ 3001, ~ A u s t r a l i a . ~ E-m a i l ~ e g r e a v e s @ m u s e u m . v i c . g o v . a u ~}$ \\ ${ }^{2}$ Senckenberg research institutes and natural history museums, German Centre for Marine Biodiversity Research, Biozentrum Grindel, \\ Martin-Luther-King-Platz 3, D-20146 Hamburg, Germany. E-mail kmeissner@senckenberg.de \\ ${ }^{3}$ Sciences Department, Museum Victoria, GPO Box 666, Melbourne, Victoria 3001, Australia. E-mail rwilson@museum.vic.gov.au
}

\begin{abstract}
Species belonging to the genus Laonice (Polychaeta: Spionidae) from continental shelf and slope depths off western and northern Australia are described. Three species are new to science (L. lemniscata, L. insolita, L. pectinata), two additional species of uncertain identity are recognised from incomplete material and are similar to existing species. A key is provided to allow identification of all six Laonice species known from Australia. Also, a new standard for the observation of hooded hooks in Laonice is established. One of the Australian species, L. quadridentata, belongs to a group of Laonice species with fused prostomium and peristomium. These species are of great morphological similarity and several are reported to exhibit ontogenetic and individual variability and we discuss the significant taxonomic problems that are a consequence of that variability. The faunas of the continental margin of western and northern Australia were poorly sampled prior to the extensive surveys that generated our study material; this study and other current work suggests that our present estimates of species richness of the Australian marine invertebrate fauna significantly underestimate species richness, perhaps by as much as $50 \%$.
\end{abstract}

Key words: Continental shelf, continental slope, key, ontogenetic variation, hooded hooks

\section{Introduction}

The genus Laonice comprises species of Spionidae with an anteriorly expanded prostomium, reduced peristomial wings, branchiae from chaetiger 2, and nuchal organs that extend posteriorly for a variable number of chaetigers. Most species also have an occipital antenna, neuropodial hooded hooks and sabre chaetae, branchiae that are separate from or partly fused with notopodial lobes, and interparapodial genital pouches. According to the parsimony analysis of Sigvaldadóttir et al. (1997), Laonice is a sister taxon to Spiophanes, that clade being defined by long nuchal organs and branchiae continuing to the median part of the body (though the latter are presumably secondarily lost in Spiophanes). Although it has been claimed that Laonice "appears unambiguously monophyletic" (Radashevsky \& Lana 2009: 265), there has been no phylogenetic analysis testing membership of all species assigned to the genus. Nevertheless, authors have had no difficulty in consistently recognising species as belonging to Laonice: the 19 species recognised in Table 1 of Maciolek (2000) are those recognised by earlier authors, with a further 10 species having been described since (Aguirrezabalaga \& Ceberio 2005; Radashevsky \& Lana 2009; Sigvaldadóttir \& Desbruyeres 2003; Sikorski 2003a,b). We assemble the current list of accepted species of Laonice in Table 1, also see the Discussion section following the species accounts. The new species described in this paper, also included in Table 1, have not altered the generic description, although they continue to confirm some of the 'exceptions' (such as a species with notopodial hooded hooks and no occipital antenna).

Although assignment of species to Laonice has been uncomplicated, defining species boundaries within Laonice has been more problematic. Characters such as the first occurrence of sabre chaetae need to be used with caution, as the most anterior sabre chaetae move posteriorly as specimens grow, therefore a full range of specimen sizes is required to ensure complete understanding of a species (Radashevsky \& Lana 2009). Where sufficient 


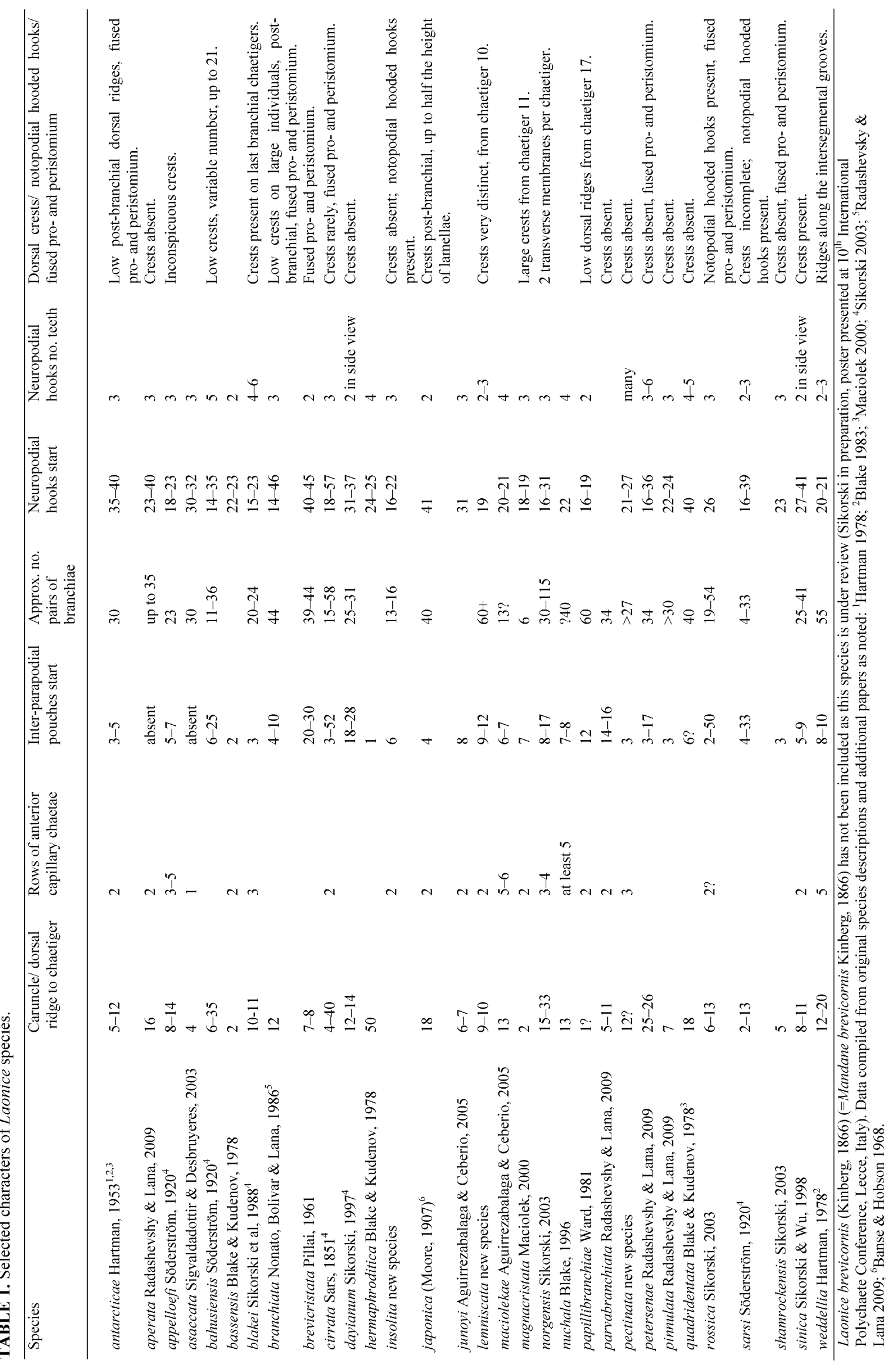


material is available, a morphometric approach gives robust results (Radashevsky \& Lana 2009; Sikorski 2002, 2003a) but in other situations a combination of variable characters including position of hooded hooks, nuchal organs, and interparapodial pouches has been used (Maciolek 2000; Sigvaldadóttir \& Desbruyeres 2003). Whether hooded hooks are bi- or tri-dentate has until recently been assumed to be consistent but it is now known that this character may also be variable and difficult to observe so should be used with caution as shown in this study and by earlier authors (Radashevsky \& Lana 2009). Further discussion of variability of the form of hooded hooks and methods for their examination using light and scanning electron microscopy is provided below.

\section{Material and methods}

Sources of material. Specimens from Western Australia were obtained through a survey of the continental margin from Albany in the south to Ashmore Reef in the north from depths of 100-1000 m (voyages SS07/2005, SS082005, SS 10/2005, SS05/2007 of RV Southern Surveyor). Additional material, from the Gulf of Carpentaria in northern Australia, collected during the Gulf of Carpentaria Seabed Biodiversity Survey (voyage SS03/2005 of RV Southern Surveyor) in March 2005 has also been included. The goals of these surveys were to improve biodiversity data available for marine environmental planning in Australia by sampling in poorly known regions; further details of the Western Australian sampling program are provided by Poore et al. (2008) and Williams et al. (2010). Locations from which Laonice material was generated from these surveys, and known distributions of other Australian Laonice species, are shown in Figure 1. Depth ranges of species are illustrated in Figure 2.

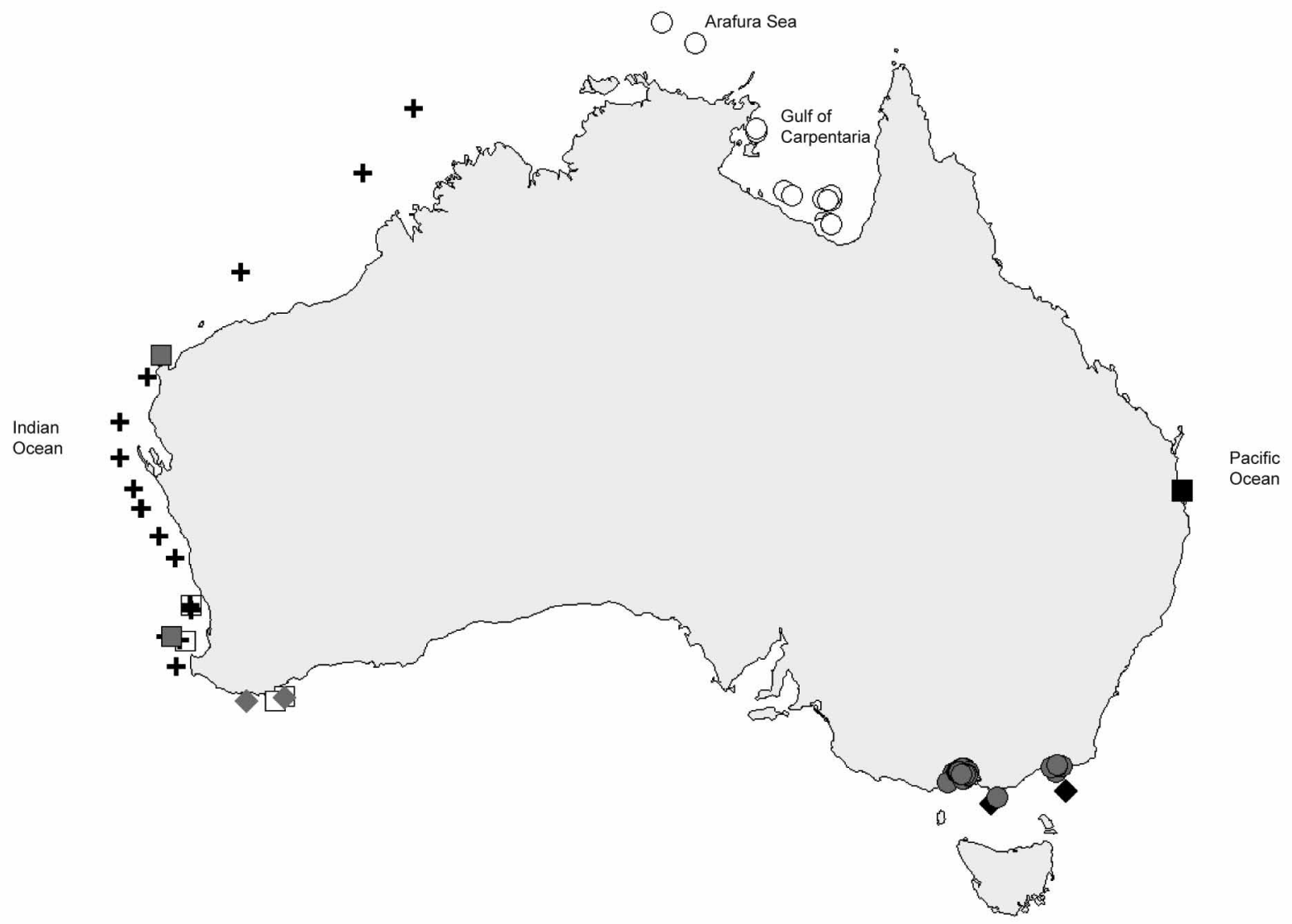

FIGURE 1. Locations in Australia where Laonice specimens were collected. Cross: L. insolita. White circle: L. cf. quadridentata. Grey circle: L. quadridentata. White square: L. lemniscata. Grey square: L. pectinata. Black square: L. hermaphroditica (data from unpublished Museum Victoria data). Grey diamond: Laonice cf. weddellia. Black diamond: L. bassensis (data from Blake \& Kudenov 1978).

Material examined lists use the following abbreviations. ZMH-Zoological Museum, University of Hamburg, Hamburg, Germany; MV—Museum Victoria, Melbourne, Australia; QM-Queensland Museum, Brisbane, Aus- 
tralia; SMF-Senckenberg Museum, Frankfurt-am-Main, Germany; ZSRO-Zoological Collection of the University of Rostock, Rostock, Germany. Within material examined 'af' = anterior fragment and 'mf' = median fragment.

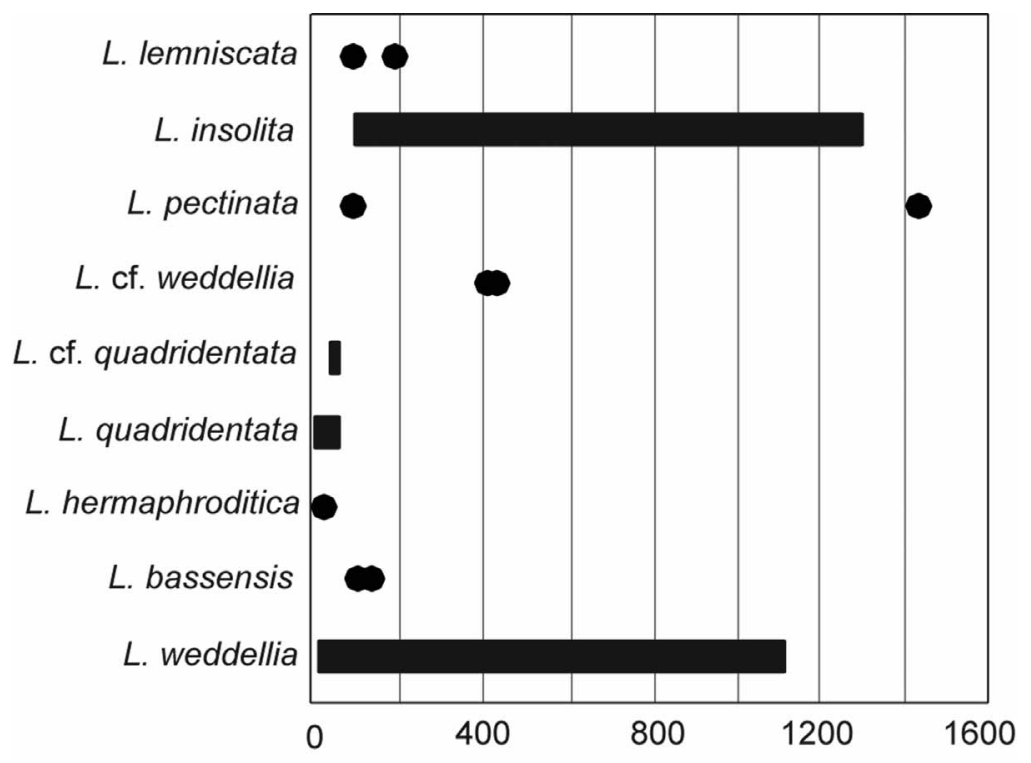

FIGURE 2. Bathymetric distribution of Australian Laonice species. L. hermaphroditica data based on the depth of Morton Bay, L. bassensis data from Blake \& Kudenov 1978, L. weddellia data from OBIS (http://www.obis.org.au/)

Description of characters and procedures. Observation of characters was facilitated by the use of methyl green staining using methods similar to those previously employed in other polychaete studies (Meißner \& Hutchings 2003; Winsnes 1985); specimens are transferred into water first and then dipped into a methyl green solution diluted with water. The stain fades quickly when specimens are returned to ethanol.

The position of interparapodial pouches is described using the anterior edge of the pouches. For example, 'pouches present from 9-16' means that the first pouch is present between chaetigers 9 and 10 and the last pouch is between chaetigers 16 and 17 .

The chaetiger on which the hooded hooks and sabre chaetae are first present is recorded in the descriptions to remain consistent with other Laonice descriptions. As some descriptions are based on relatively few specimens, unrepresentative of all size classes, this information is unlikely to be sufficient for complete identification. Additionally, the starting position of sabre chaetae can be difficult to determine as there is frequently a transitional stage where there are chaetae with the diameter of normal neuropodial capillaries in the inferior-most position, which are replaced by one or more stout chaetae that more closely fit the traditional description of sabre chaetae. The separation of sabre chaetae from the neuropodial capillaries in this transitional area is particularly difficult in species with rather stout granulated capillaries.

Width was measured at chaetiger 10, excluding parapodia. To give an indication of size, branchial length is described relative to the portion of the notopodial lobe that extends above the dorsum.

Hoods on noto- and neuropodial hooks were removed following the method of Nishino \& Ohwada (1991). Individual parapodia were removed, and placed in distilled water in a vial, which was then placed in a Bendelin Sonorex Super 10P ultrasonic bath for varying amounts of time ( $30 \mathrm{sec}$ to $15 \mathrm{~min}$ in the bath) at varying frequencies until the hoods had been obviously removed when checked using a microscope. No pattern could be determined regarding the time or frequency required to remove the hoods, so short periods at low frequencies with frequent checking is recommended. Parapodia were then mounted on stubs, sputter coated, and viewed with the Leo Gemini 1525 scanning electron microscope.

\section{Systematics}

Laonice lemniscata sp. nov.

Figures 3-4 
Material examined. Holotype: Australia: Indian Ocean, Albany region, T6 200, Stn SS07/2005 183, 35²1.5' S 118 17.4' E, 9 Jan 2005, 193 m, MV F167370. Paratypes: Indian Ocean, Two Rocks region, T4 200, Stn SS07/ 2005 134, 31 38.9' S, $115^{\circ} 1.267^{\prime}$ E, 4 Jan 2005, 196 m, 1 specimen, MV F111057; Indian Ocean, Bald Island region, T7 100, Stn SS07/2005 195, 35 10.65' S, 118³7.917' E, 10 Jan 2005, 102 m, 1 specimen, MV F158711; Indian Ocean, Bunbury region, L13 100, Stn SS07/2005 213, 33².3' S, 11448.483' E, 14 Jan 2005, 102 m, 1 specimen, MV F110637; Indian Ocean, Albany region, T6 200, Stn SS07/2005 183, 35²1.5' S, 118¹7.4' E, 9 Jan 2005, 193 m, 1 specimen, MV F167372.

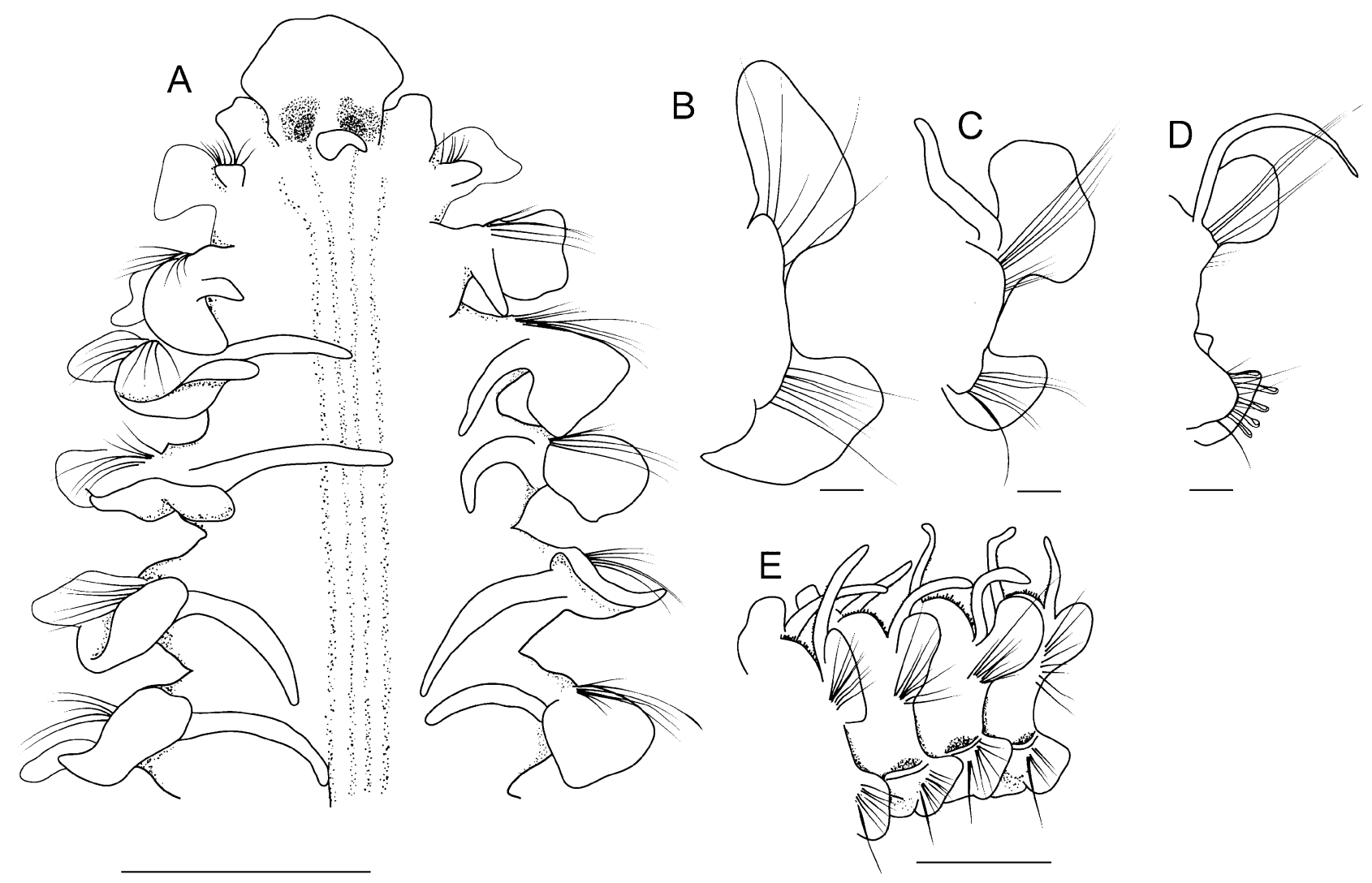

FIGURE 3. Laonice lemniscata sp. nov. holotype. A. Anterior end, dorsal view. B. Parapodium 10 (left), branchia lost. C. Parapodium 18 (left). D. Parapodium 25 (left). E. Chaetigers 15-19, anterolateral view. Scales: A-E 0.5 mm.

Description. All specimens anterior fragments, 18-35 chaetigers except nearly complete holotype (MV F167370) with 61 chaetigers, 2.3-15 mm long (holotype $15 \mathrm{~mm}$ ), 0.3-0.8 $\mathrm{mm}$ wide.

Prostomium blunt, anteriorly rounded, entire or very slightly indented; without frontal or lateral horns. Caruncle present, continuous with prostomium, narrowing at about level of chaetiger 2, then extending back to chaetiger 9 or 10 (difficult to determine due to split dorsum). Long, finger-like occipital antenna present on posterior part of prostomium, behind eyes. Eyes present as one pair, each a dark brown to reddish patch edged anteriorly and laterally by lighter brown crescent. Peristomium separate from prostomium, approximately half the length of prostomium. Palps lost from all specimens. Nuchal organ long, U-shaped, extending posteriorly to about chaetiger 15 or 16 (difficult to determine due to split dorsum) (Fig. 3A).

Dorsal branchiae present from chaetiger 2 to near posterior end of body. Branchiae free, separate from notopodial lamellae throughout; all simple, distinctly ciliated on inner margin; longest on anterior third of specimen, first branchiae approximately same length as notopodial lobe, by about chaetiger 7 approximately twice length of notopodial lobe, and in posterior half up to three times length of lobes (due in part to the smaller size of the notopodial lobe).

Notopodial postchaetal lobes reduced to small subtriangular projection on chaetiger 1; then leaf-like and slightly pointed until about chaetiger 4 , then becoming more rounded and gradually reduced to small round lobes. Neuropodial postchaetal lobes leaf-like from chaetiger 1; dorsally rounded and ventrally pointed until about chaeti- 
ger 15, then rounded and reduced in size; small by about chaetiger 25(Fig. 3B-D). Dorsal crests present from chaetiger 10, initially separated by nuchal organ/caruncle, full, ciliated crests from chaetiger 13 and on all remaining chaetigers. Additional transverse ciliation present on segmental margins. Interparapodial pouches on chaetigers 961; starting from chaetiger 9-11 and continuing posteriorly to end of fragment (Fig. 3E).

Anterior capillaries in two rows in both noto- and neuropodia, anterior row generally stout and short. Posterior neuropodial capillaries narrower and fewer than anterior. Neuropodial hooded hooks begin from chaetiger 17-22, 4-5 per fascicle, bi- or tridentate (tooth above main fang may or may not have smaller apical tooth) (Fig. 4A-B). Neuropodial sabre chaetae first present on chaetiger 10-11, 1-2 per fascicle.

Pygidium unknown.

Colour. White (unpigmented) in ethanol.

Distribution. Southwestern Australia, shelf, 102-196m (Figs. 1-2).

Remarks. The prominent dorsal crests distinguish this species from other known Laonice species. Of the descriptions that mention dorsal crests, the majority describe them as low or incomplete, not reaching the dorsal midline, except L. japonicus (Moore, 1907) and L. magnacristata Maciolek, 2000, which both have large dorsal crests. The crests of L. japonicus start around chaetiger 38, much later than those of L. lemniscata sp. nov.. Laonice magnacristata has crests starting on chaetiger 11, similar to L. lemniscata sp. nov., but has a very limited number of branchiae (6 pairs compared to over 50 pairs in L. lemniscata sp. nov.).

Etymology. Latin for 'adorned with ribbons' lemniscata refers to the appearance of the long, thin branchiae of this species.

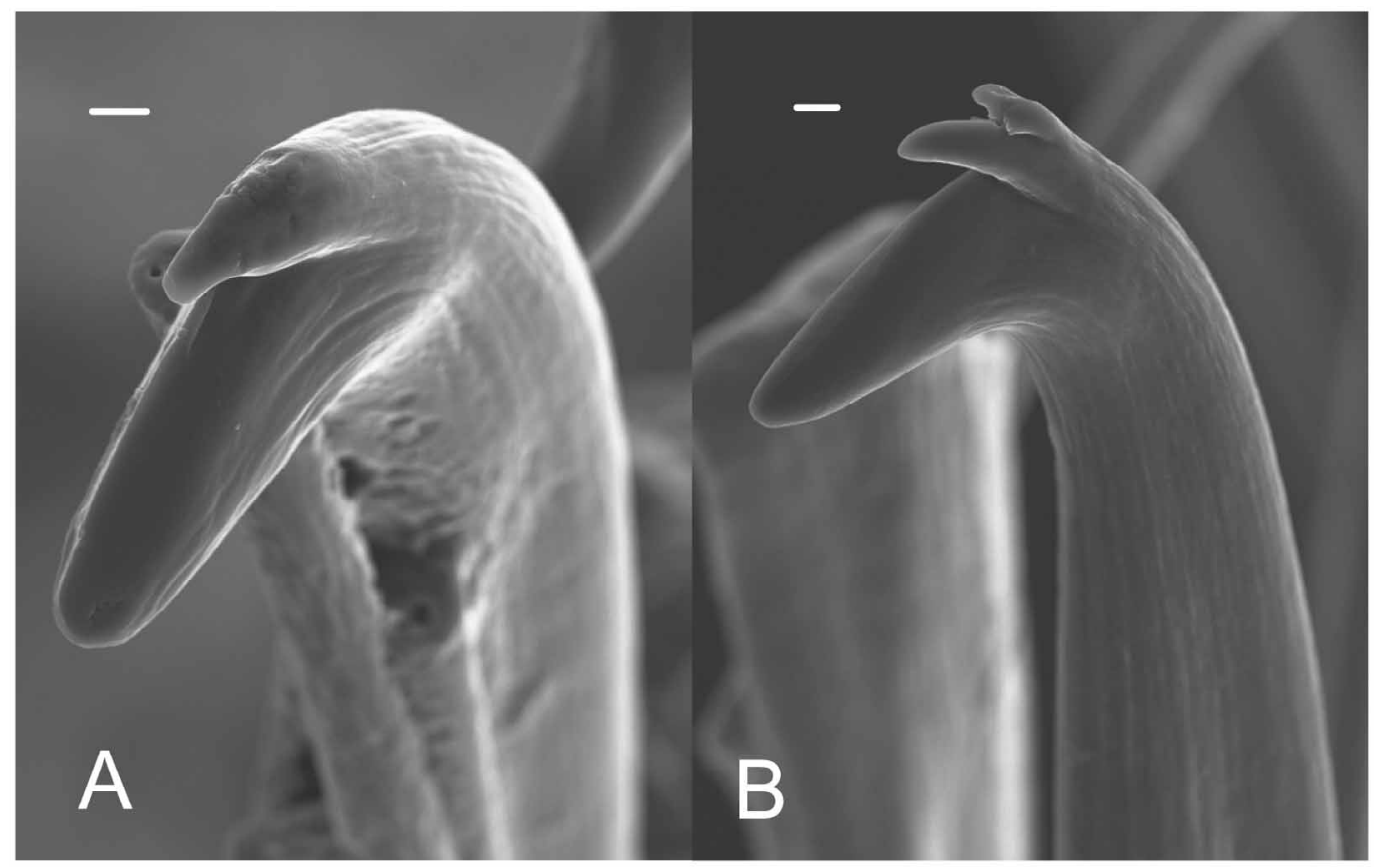

FIGURE 4. Laonice lemniscata sp. nov., holotype. A. Chaetiger 33 neuropodial hook, hood removed. B. Chaetiger 22 neuropodial hook, hood removed. Scales: A-B $1 \mu \mathrm{m}$.

\section{Laonice insolita sp. nov.}

Figures 5-7

Material examined. Holotype: Indian Ocean, Shark Bay region, L6, Stn SS07/2005 81, 2557.583' S, $112^{\circ} 15.417^{\prime}$ E, 28 Jan 2005, 393 m, MV F110764. Paratypes: Indian Ocean, Shark Bay region, L6, Stn SS07/2005 $80,25^{\circ} 57.567^{\prime} \mathrm{S}, 112^{\circ} 15.233^{\prime} \mathrm{E}, 28 \mathrm{Jan} 2005,404 \mathrm{~m}, 1$ specimen, MV F110725; Indian Ocean, Shark Bay region, L6, Stn SS07/2005 81, 25 57.583' S, 112 ${ }^{\circ} 15.417^{\prime}$ E, 28 Jan 2005, 393 m, 1 specimen, MV F110763; Indian Ocean,

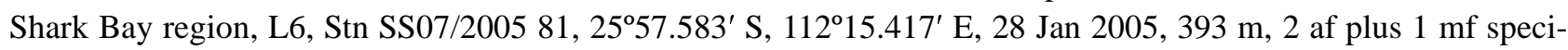
mens, ZMH-P25871 (ex MV F110727); Indian Ocean, Shark Bay region, L6, Stn SS07/2005 81, 2557.583' S, 
$112^{\circ} 15.417^{\prime}$ E, 28 Jan 2005, 393 m, 2 af plus 1 mf specimens, ZSRO-P2062 (ex MV F110727); Indian Ocean, Kal-

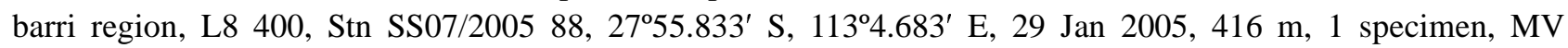

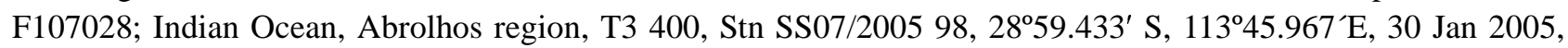
388 m, 1 specimen, MV F110741.

Additional material examined. Australia: Indian Ocean, Point Cloates region, L3, Stn SS07/2005 68, $22^{\circ} 51.533^{\prime}$ S, 113 19.683' E, 27 Jan 2005, 448 m, 7 specimens, MV F167393; Indian Ocean, Shark Bay region, L6,

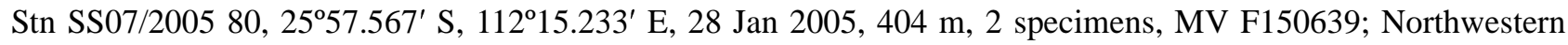
Australia, Leveque L27 transect, Stn SS05/2007 137, 14 ${ }^{\circ} 58.233^{\prime} \mathrm{S}, 121^{\circ} 38.933^{\prime} \mathrm{E}, 230 \mathrm{~m}, 1$ specimen, MV F110739; Northwestern Australia, Karratha L21 transect, Stn SS05/2007 042, 1846.45' S, 116 $555.033^{\prime}$ E, 400 m, 1

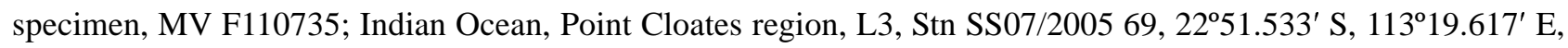
27 Jan 2005, 451 m, 3 specimens, MV F110733; Indian Ocean, Zyutdorp region, L7 400, Stn SS07/2005 85, $27^{\circ} 10.05^{\prime}$ S, 112 $12^{\circ} 6.683^{\prime}$ E, 29 Jan 2005, 375 m, 2 specimens, MV F110753; Indian Ocean, Kalbarri region, L8

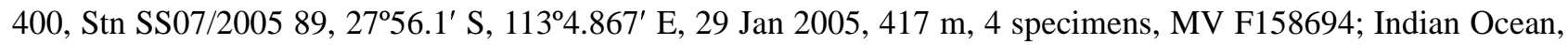

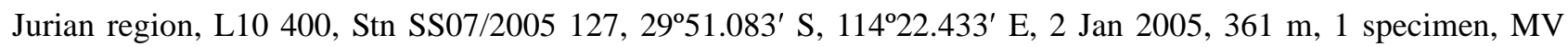

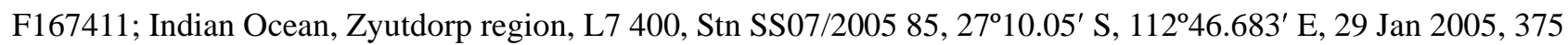
m, 8 specimens, MV F158685; Indian Ocean, Abrolhos region, T3 400, Stn SS07/2005 98, 2859.433' S, 1134․ $967^{\text {`E, }} 30$ Jan 2005, 388 m, 2 specimens, MV F167416; Indian Ocean, Two Rocks region, T4 400, Stn

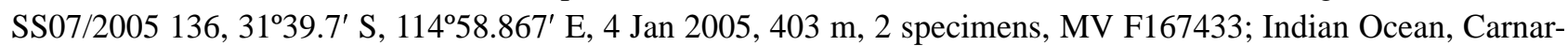

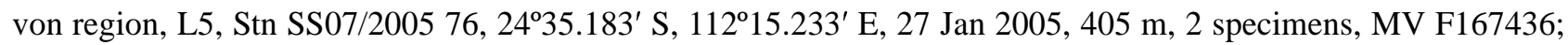

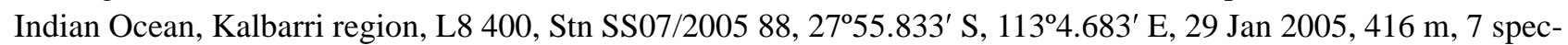
imens, MV F110606; Indian Ocean, Carnarvon region, L5, Stn SS07/2005 75, 24³5.25' S, 112 ${ }^{\circ} 15.183^{\prime}$ E, 27 Jan 2005, 405 m, 2 specimens, MV F110609; Indian Ocean, Point Cloates region, L3, Stn SS07/2005 69, 22 ${ }^{\circ} 51.533^{\prime}$ S, 113 ${ }^{\circ} 19.617^{\prime}$ E, 27 Jan 2005, 451 m, 1 specimen, MV F110618; off Pelsart Island, near Geraldton, Stn SS07 2005 $122,2^{\circ} 0.167^{\prime} \mathrm{S}, 113^{\circ} 46.433^{\prime} \mathrm{E}, 409$ m, 6 specimens, MV F110626; Indian Ocean, Zuytdorp region, L7 400, Stn

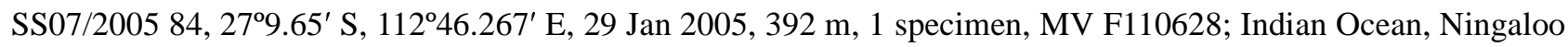

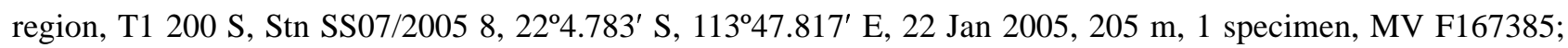

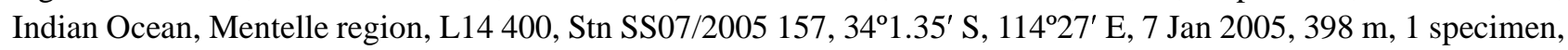

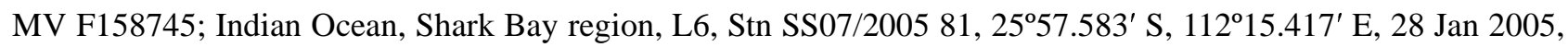

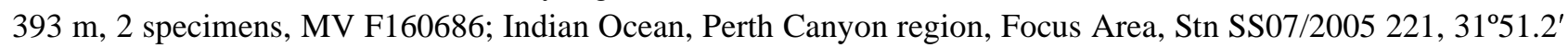
S, $115^{\circ} 1.317^{\prime}$ E, 15 Jan 2005, 413 m, 2 specimens, MV F158751; Indian Ocean, Bunbury region, L13 400, Stn

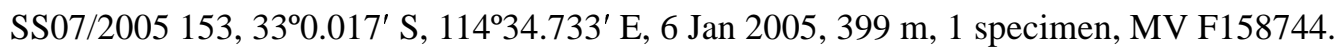

Description. Six complete specimens, remainder anterior fragments only, entire specimens $2.2-16 \mathrm{~mm}$ long, $0.1-0.7 \mathrm{~mm}$ wide (holotype $16 \mathrm{~mm}$ long, $0.5 \mathrm{~mm}$ wide).

Prostomium blunt, broadly rounded, entire. Posterior margin of prostomium not discernable as completely fused with dorsum, lateral margin of prostomium defined by low dorsolateral ridges that continue until posterior margin of chaetiger 1 (Fig. 6A). Occipital antenna absent. Four small eyes present, generally pale and deep-set. Peristomium separated from prostomium, not well developed. Palps simple, with double undulating ridge; about 12 chaetigers long. No nuchal organ observed (Figs. 5A-B; 6A).

Dorsal branchiae present from chaetiger 2 to about chaetiger 14-17 (chaetiger 7-8 in small specimens); branchiae free, separate from notopodial lamellae throughout; all branchiae similar in width and size to notopodial lobe, except chaetiger 2, which is about half the length, last few pairs also slightly shorter (Figure 5E-F, 6A-F).

Both notopodial and neuropodial postchaetal lobes relatively small, short and tapering. Anteriorly, notopodial lobes thin and tapering, neuropodial lobes similar but slightly more triangular. Posteriorly, both notopodial and neuropodial lobes somewhat triangular (Figs. 5E-F, 6E-F). Dorsal crests absent (Figs. 5A-B, 6A-F). Interparapodial pouches present on chaetigers 6-18; beginning between chaetigers 6 and 7 regardless of specimen size, terminating chaetiger 10-12 on smaller specimens, chaetiger 15-18 on larger specimens; some anterior pouches with additional dorsal flap from above, connected to anterior end of pouch (Fig. 6E); termination of pouches somewhat correlated with last branchiae. 

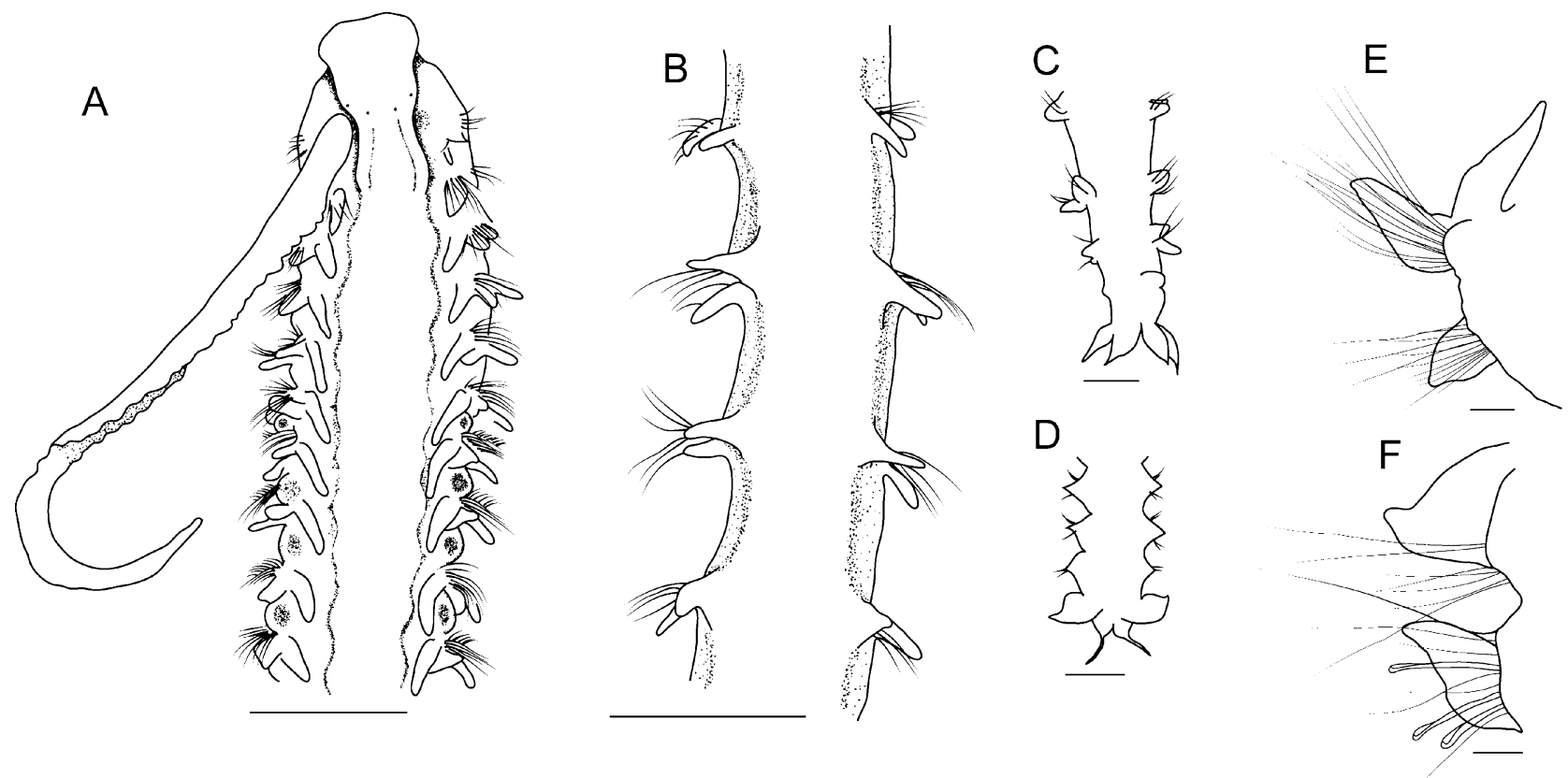

FIGURE 5. Laonice insolita sp. nov. (MV F110725 except where noted). A. Anterior end, dorsal view. B. Chaetigers 21-24, dorsal view. C. Pygidium (MV F110606), dorsal view. D. Juvenile pygidium (MV F110741), dorsal view. E. Parapodium 5 (right). F. Parapodium 34 (right), branchia lost. Scales: A-B $0.5 \mathrm{~mm}$; C-D $0.1 \mathrm{~mm}$; E-F $0.05 \mathrm{~mm}$.

A short row of 6-9 pits (sometimes accompanied by a row of smaller pits) present on dorsum from chaetiger 6 , near base of branchiae and intersegmental boundary (Fig. 6C-D).

Anterior capillaries in two rows; only a single row and fewer capillaries per fascicle posteriorly; capillaries of similar width throughout. Notopodial hooded hooks beginning from chaetiger 20-40, tridentate, main fang surmounted by pair of apical teeth somewhat perpendicular to main fang (Fig. 6G). Neuropodial hooded hooks first present from chaetiger 16-22, tridentate, similar to notopodial hooks. Neuropodial sabre chaetae absent.

Pygidium with four large leaf-shaped cirri, small specimens with two large leaf-shaped cirri and two thin, elongated cirri (Fig. 5C-D).

Colour. White (unpigmented) in ethanol.

Distribution. Western coast of Australia, 205-451 m (Figs. 1-2).

Remarks. This species has many characters that are not typical of Laonice species; however, placement in this genus is justified as most of these characters are present in at least one other described species in the genus. The defining specific characters include the absence of an occipital antenna, the presence of notopodial hooded hooks (with apical teeth that are more perpendicular to the main fang than in other Laonice species), the lack of sabre chaetae, a reduced number of branchiae (generally 12-15 pairs), and interparapodial pouches always starting between chaetigers 6 and 7 and ending between chaetiger 10 and 18. The early termination of both branchiae and interparapodial pouches results in an obvious division between the anterior and posterior regions, giving this species a distinctive appearance.

Laonice brevicristata Pillai, 1961, L. shamrockensis Sikorski, 2003, and L. dayianum Sikorski, 1997 have all been described as lacking an occipital antenna. Maciolek (2000) noted that both L. brevicristata and L. dayianum need to be reevaluated, especially the latter, which was illustrated as having at the least the scar of an occipital antenna. Regardless, all three species have sabre chaetae and interparapodial pouches that begin much later than the species described here. The SEM photo (Fig. 6A) shows a small ridge across the prostomium. This structure is not visible on other specimens using the light microscope, and it is not in a position typical of the occipital antenna (the ridge seen is anterior to the position of the eyes) and so is not thought to be homologous with this structure.

Laonice sarsi Söderström, 1920 is the only other species in the genus reported to have notopodial hooded hooks (Maciolek 2000). However, it has interparapodial pouches that start later, at chaetigers 14-28, rather than at setiger 6 as in L. insolita sp. nov. 
Due to the large number of specimens available, it was possible to study size dependency of characters in this species. The difficulty of measuring size (in the form of width) in such small specimens means that some resolution has most likely been lost, however the general trend can be observed (Fig. 7).

Etymology: Latin for 'unusual, uncommon, strange', insolita refers to the many characters of this species that are uncommon in other Laonice species.

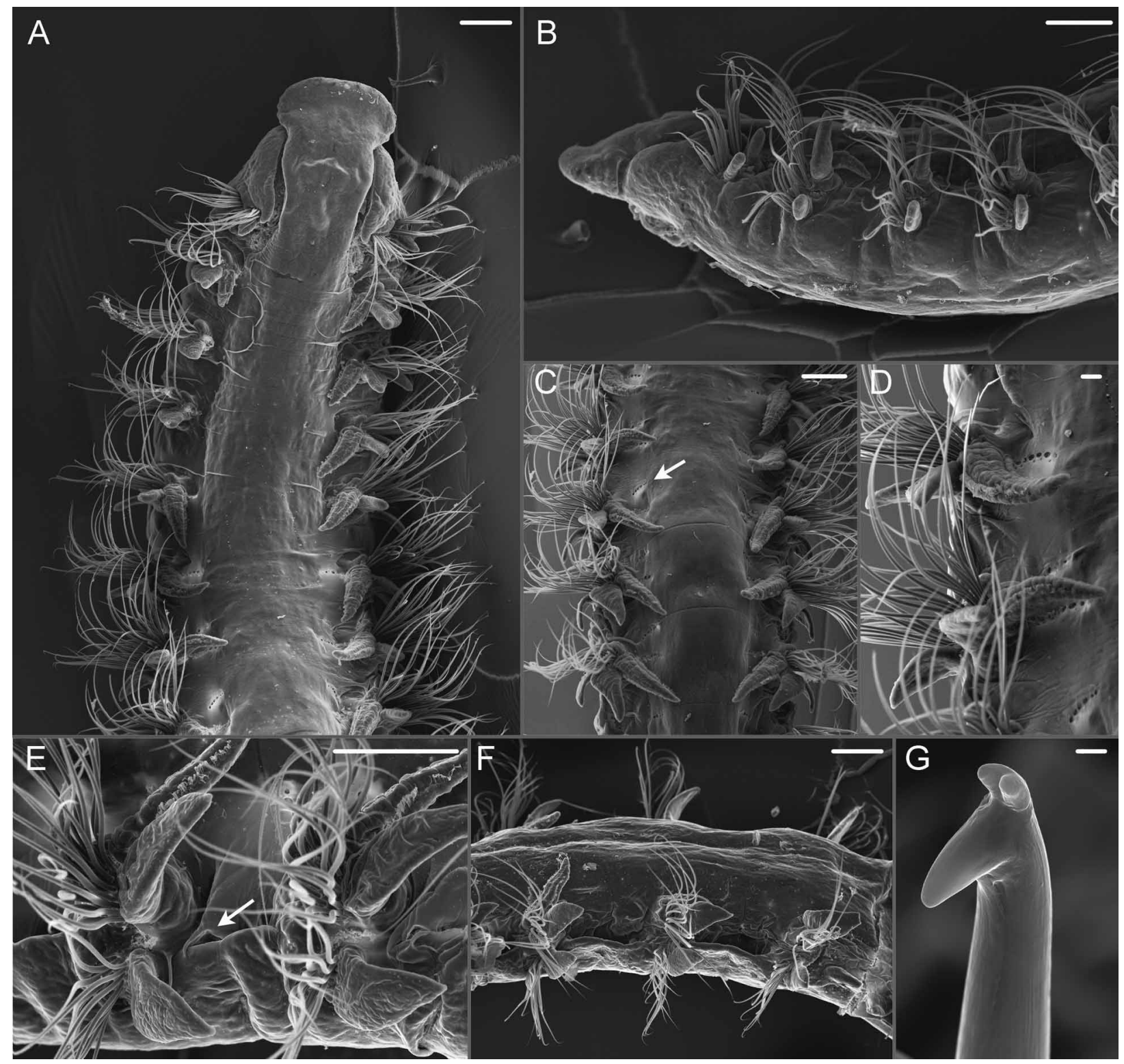

FIGURE 6. Laonice insolita sp. nov. (ZMH-P25871). A. Anterior end, dorsal view. B. Anterior end, lateral view. C. Chaetiger 6-10 from dorsal, arrow indicating row of tiny holes present near the notopodial base. D. Left side of chaetiger 6 and 7 from dorsal. E. Interparapodial pouch between chaetigers 8-9, arrow indicating additional flap from above. F. Chaetigers 16-18 with interparapodial pouches. G. Neuropodial hook from chaetiger 37, hood removed. Scales: A-C, E, F $100 \mu$ m; D $20 \mu \mathrm{m}$; G $1 \mu$ m. 


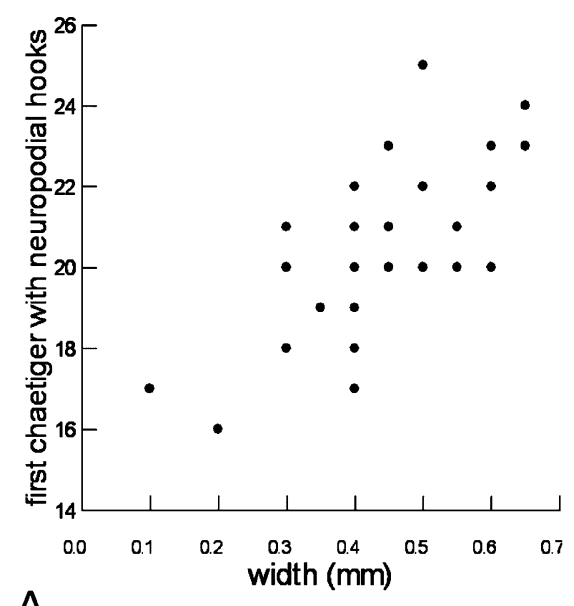

A

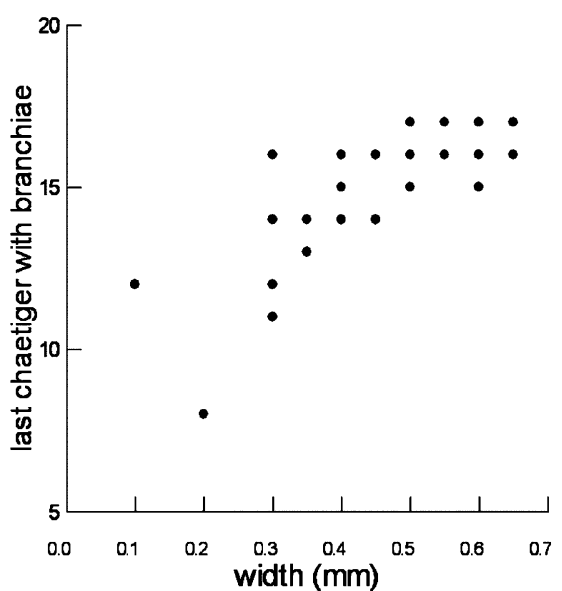

B

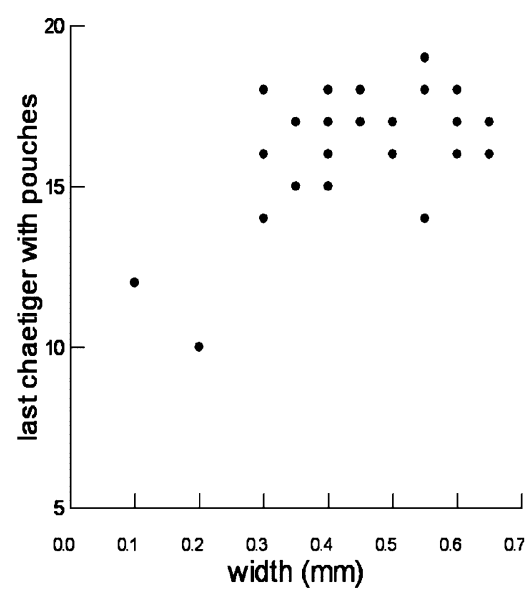

C

FIGURE 7. Laonice insolita sp. nov. Morphometric data. A. first chaetiger with neuropodial hooks. B. last chaetiger with branchiae. C. last chaetiger with interparapodial pouches. All in relation to body width.

\section{Laonice pectinata sp. nov.}

Figures 8-9

Material examined. Holotype: Australia: Indian Ocean, west of Perth, Stn SS082005 25BS02, 32 $2^{\circ} 1.267^{\prime}$ S, $114^{\circ} 15.417^{\prime}$ E, 14 Oct 2005, 1440 m, MV F150655. Paratypes: Indian Ocean, west of Perth, Stn SS082005 25BS02, 32 $51.267^{\prime} \mathrm{S}, 114^{\circ} 15.417^{\prime} \mathrm{E}, 14$ Oct 2005, $1440 \mathrm{~m}, 1$ specimen, MV F110722; Indian Ocean, west of Perth, Stn SS082005 25BS02, 32 $51.267^{\prime}$ S, $11^{\circ} 15.417^{\prime}$ E, 14 Oct 2005, 1440 m, 3 specimens, MV F110724; Indian Ocean, Ningaloo North region, T2 100, Stn SS07/2005 17, 21 ${ }^{\circ} 58.75^{\prime}$ S, 113 $50.583^{\prime}$ E, 23 Jan 2005, 99 m, 1 specimen, MV F167424.

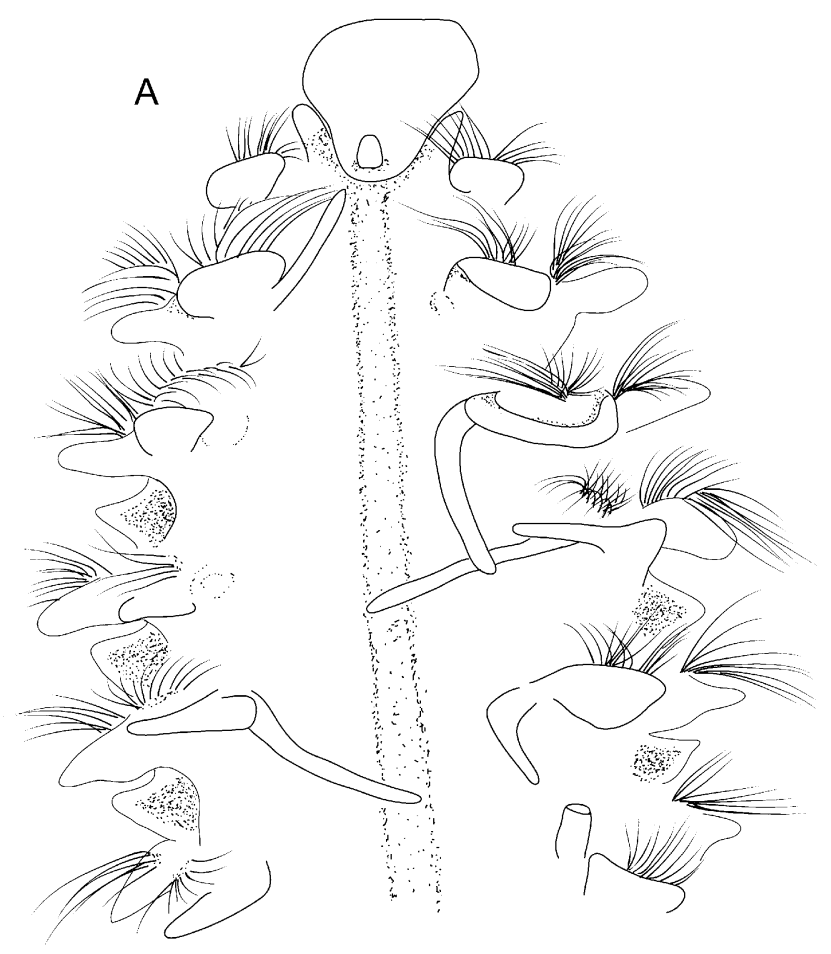

B

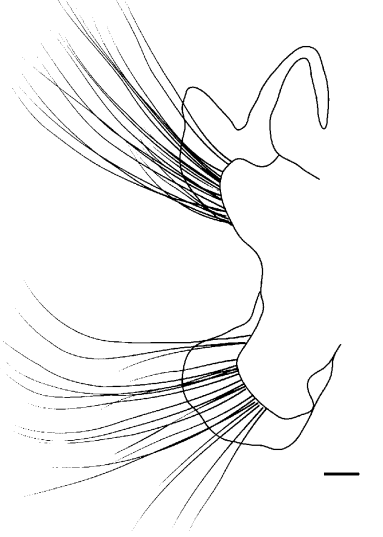

C

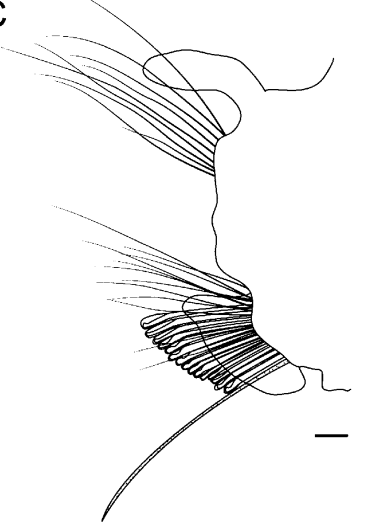

FIGURE 8. Laonice pectinata sp. nov. (MV F150655 except where noted). A. Anterior end, dorsal view; branchiae lacking on chaetigers 2 (right side only) and 3, 4, 6 (left side only) (MV F110724). B. Parapodium 5 (right). C. Parapodium 23 (right, notopodial lobe lost during dissection). Scales: A $0.5 \mathrm{~mm}$; B-C $0.05 \mathrm{~mm}$. 


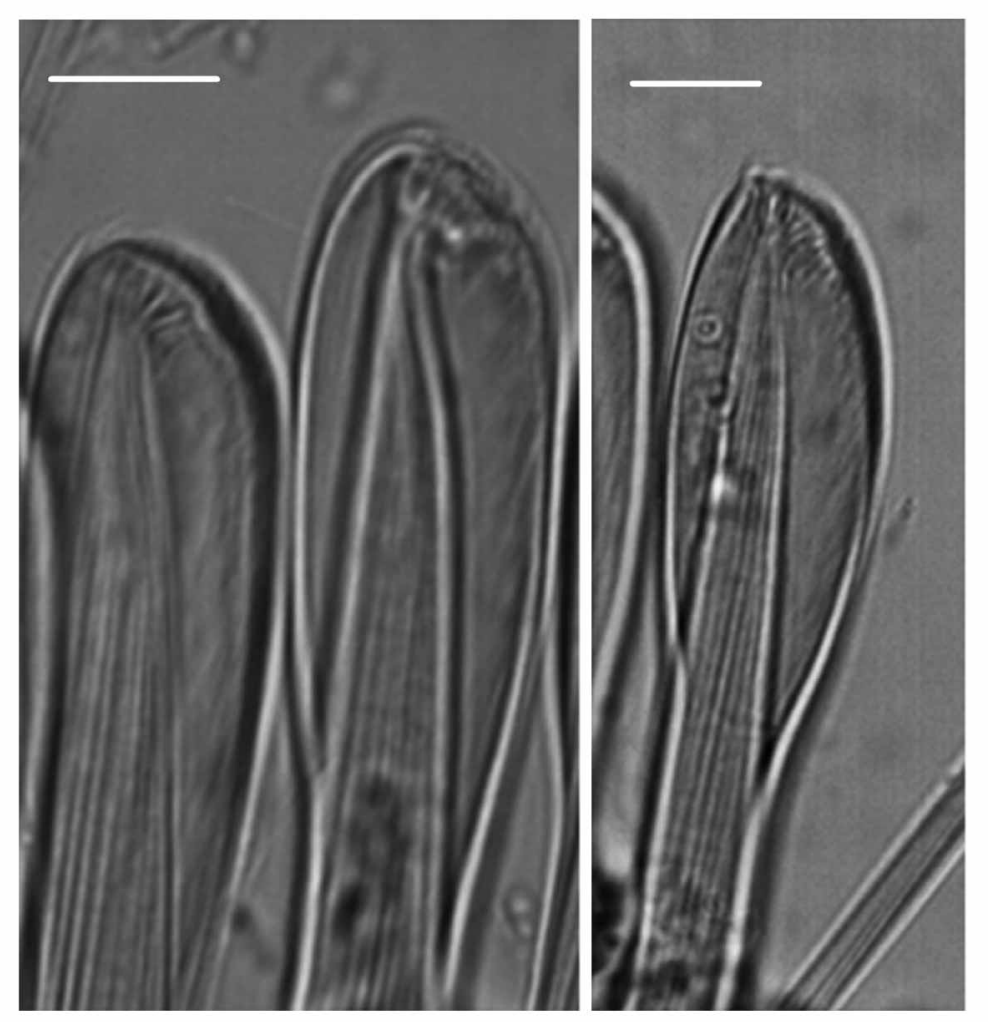

FIGURE 9. Laonice pectinata sp. nov. (MV F150655). A, B. Neuropodial hooded hooks, chaetiger 23. Scales: A-B 0.01 mm.

Description. All anterior fragments, longest 27 chaetigers; in relatively poor condition, $3.5-5.5 \mathrm{~mm}$ long, $0.5-$ $1 \mathrm{~mm}$ wide.

Peristomium separate from prostomium, narrow, approximately half length of prostomium. Prostomium blunt, somewhat rounded, entire, extending posteriorly to chaetiger 1, terminating with occipital antenna, not fused to dorsum for posterior third of length; dorsal ridge extending posteriorly at least 12 chaetigers, uncertain due to specimen condition. Short occipital antenna present. Eyes present or absent; two pairs of eyes visible on one specimen (MV F167424); absent from remaining specimens. Palps lost from all specimens.

Dorsal branchiae from chaetiger 2 to end of fragments; free and separate from notopodial lamellae throughout; slender, up to twice length of notopodial postchaetal lamellae, appear to fall off more easily than in some other species.

First notopodial postchaetal lobe small, increasing in size until about chaetiger 4, leaf-shaped, somewhat pointed dorsally, becoming larger and more rounded, ultimately becoming kidney-shaped. Neuropodial postchaetal lamellae small rounded lobes throughout. Dorsal crests absent. Interparapodial pouches present, beginning chaetiger 3, until at least chaetiger 13 (after which they are difficult to recognise due to preservation).

Notopodial capillary chaetae in three rows, becoming more dense until about chaetiger 10, then reducing in number until end of fragment. Anterior neuropodial capillaries in three rows, stout; reduced to two rows, more slender and confined to upper part of neuropodium posteriorly. Neuropodial hooded hooks begin from chaetiger 21-27, up to 20 per fascicle, with many accessory teeth and no discernable main fang (Fig. 9A-B). Neuropodial sabre chaetae present, in ventral-most position, beginning chaetiger 9-14, two per fascicle, occasionally only a single sabre chaeta present.

Pygidium unknown.

Colour. White (unpigmented) in ethanol.

Distribution. Western Australia, 99-1440 m (Figs. 1-2).

Remarks. This species is easily distinguished from other Australian species by the presence of up to 20 neuropodial hooded hooks per fascicle, each with numerous teeth. Hood removal by ultrasound was unsuccessful and due to limited hooks on the few available fragments, further attempts were not undertaken and hence SEM studies could not be conducted. Unfortunately this means that the exact number of teeth remains unknown, but the shape is 
clearly distinguishable under a light microscope. It is most similar to Laonice blakei Sikorski, Jirkov \& Tsetlin, 1988, which is known only from the Arctic; that species also has interparapodial pouches regularly starting from chaetiger 3 and three rows of chaetae on anterior chaetigers. However, hooks in L. blakei possess a distinct main fang. The species is also described as having a large occipital antenna and a caruncle to chaetiger 10-14, whereas L. pectinata sp. nov. lacks a distinct caruncle but has a dorsal ridge to about chaetiger 12 .

The sole specimen in which two pairs of eyes visible (MV F167424), was collected at $99 \mathrm{~m}$; the remaining specimens were from $1440 \mathrm{~m}$ and we cannot find any other morphological differences other than the absence of eyes in the specimens from the deeper locality. We thus treat the material as conspecific.

Laonice pectinata sp. nov. can also be characterised by having pouches consistently starting from chaetiger 3 (this feature does not appear to differ with size; however, there are only four specimens), pouches that end relatively early (about chaetiger 9-13), three rows of anterior notochaetae and often two sabre chaetae per fascicle.

Etymology: Latin for 'comblike, toothed', pectinata refers to the appearance of the neuropodial hooded hooks.

\section{Laonice cf. weddellia Hartman, 1978}

Figures 10-11

Material examined. Australia: Indian Ocean, Point Hiller region, L16 400, Stn SS07/2005 166, 35'22.85' S, $117^{\circ} 13.267^{\prime}$ E, 8 Jan 2005, 436 m, 1 specimen, MV F167421; Indian Ocean, Bald Island region, T7 400, Stn SS07/ 2005 199, 35 $12.55^{\prime}$ S, $118^{\circ} 39.533^{\prime}$ E, 10 Jan 2005, 414 m, 1 specimen, MV F158703.

Additional material examined. Laonice weddellia Hartman, 1978: Antarctica: Scotia Sea, cruise ANT 68/1 Walther Herwig, Stn 149, 61 ${ }^{\circ} 09.0^{\prime}$ S, 56 07.2' W, 24 Feb 1985, 208 m, box corer, 9 specimens, ZMH P-20854; Stn

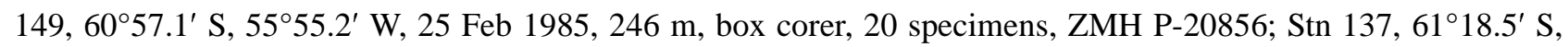

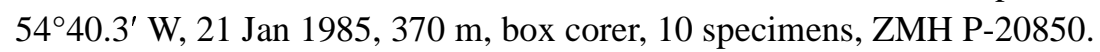

Description. (based on Western Australian specimens of Laonice cf. weddellia). Two anterior fragments, 36 and 25 chaetigers respectively, 4.3-12 mm long, 1-1.5 mm wide.

Prostomium bell-shaped, anteriorly rounded, extending posteriorly to between chaetiger 1-2. Occipital antenna present, short; arising from posterior part of prostomium, well behind eyes. Eyes present, one or three pairs; specimen with three has one anterior pair, close to edge of prostomium and relatively deeply set, second and third pairs more posterior and close together, such that on one side two eyes appear almost as one; specimen with only one pair, eyes at posterior end of prostomium and potentially composed of two closely set pairs. Peristomium separate from prostomium, well developed. Palps lost from both specimens. Nuchal organ present, extending posteriorly until approximately chaetiger 13 (difficult to determine as specimen somewhat damaged) (Fig. 10A).

Branchiae from chaetiger 2, continuing until end of fragments; initially short, similar length to notopodial lobe, approximately twice lobe length by about chaetiger 12, by end of longest fragment only just reaching beyond the lobe.

Chaetiger 1 notopodial lobes significantly smaller than those of chaetiger 2. Notopodial lobes initially rounded, gradually increasing in size, by chaetiger 4 pointed dorsally and rounded ventrally, by chaetiger 7 rounded dorsally and ventrally. Neuropodial postchaetal lobes ear-shaped, dorsal margin extending with lateral projection, becoming more triangular (Fig. 10 B-D). Dorsal crests first present chaetiger 24, continuing to end of fragments; crests less obvious on some chaetigers, appearing as mid-segmental ciliation. Interparapodial pouches present from chaetiger 9 , continuing to end of fragment.

Anterior chaetigers with 4-5 dense rows of capillary chaetae, reduced to 1-2 rows by about chaetiger 15 ; from chaetiger 5 there is a neuropodial inferior fascicle of approximately six capillary chaetae directed ventrally; by chaetiger 13 capillaries stouter and reduced in number (2-4) and probably comparable to sabre chaetae. Neuropodial hooded hooks from chaetiger 22, with paired apical teeth above the main fang (Fig. 11A-B).

Pygidium unknown.

Colour. White (unpigmented) in ethanol.

Distribution. Southern Western Australia, 414-436 m (Figs. 1-2).

Remarks. The Western Australian material resembles Laonice weddellia based on original and subsequent descriptions (Blake 1983; Hartman 1978; Radashevsky \& Lana 2009), with some variations noted: the anterior region of the Western Australian specimens has 4-5 rows of capillary chaetae for 11-12 chaetigers, rather than 14- 
15; dorsal ciliation appears to be mid-segmental instead of inter-segmental. However these differences were also observed during this study in some specimens identified as L. weddellia from Antarctica. Specimens of Laonice weddellia from the Scotia Sea, Antarctica include some specimens in which the apical teeth above the main fang of the neuropodial hooks include a smaller tooth above the paired teeth (Fig. 11C).
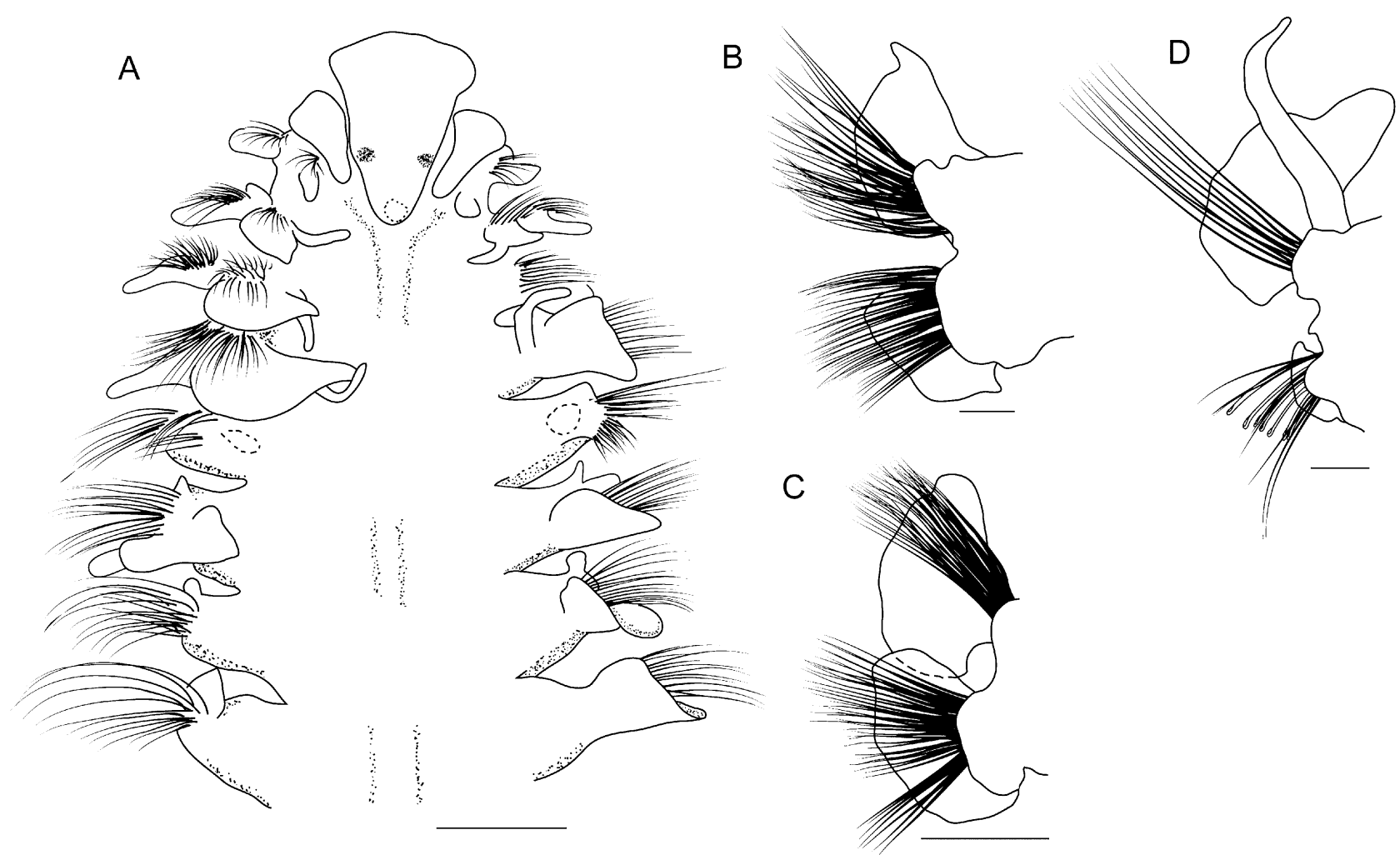

FIGURE 10. Laonice cf. weddellia (MV F167421). A. Anterior end, dorsal view; branchiae missing chaetigers 5-8. B. Parapodium 6, branchia missing (right). C. Parapodium 13, branchiae missing (right). D. Parapodium 31 (right). Scales: A, C 0.5mm; B, D $0.2 \mathrm{~mm}$.

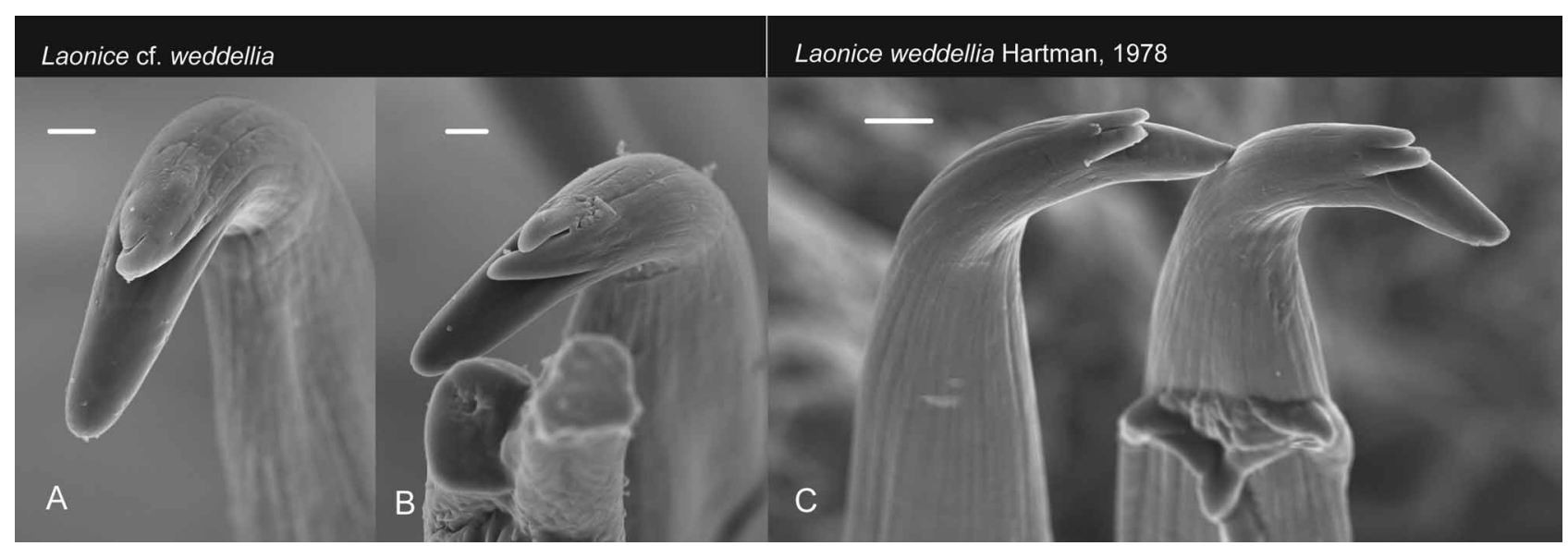

FIGURE 11. A-B Laonice cf. weddellia (MV F167421), chaetiger 25 hooded hooks, hood removed. C. Laonice weddellia Hartman, 1978 (ZMH-P20850), chaetiger 25 hooded hooks, hood removed. Scales. A-B $1 \mu \mathrm{m}$; C $2 \mu \mathrm{m}$.

Laonice weddellia Hartman, 1978 was originally described from the Weddell Sea and redescribed by Blake (1983), who expanded the distribution into other areas of the Antarctic Seas, off southern South America and the South Orkney and South Shetland Islands in depths of 44-3111 m. Radashevsky \& Lana (2009) further reported the species from Brazil and discussed the need for this species to be reassessed given the unusual distribution. More specimens, including material suitable for genetic analysis, will be required from widespread localities to determine if the specimens identified as Laonice weddellia and already encompassing a wide geographic and 
bathymetric range represent intraspecific variation or separate species in a widely-distributed species complex. Based on the variation noted above and the wide and disjunct distribution of our material, the latter explanation seems most likely to us and we prefer a conservative approach and refer the material from Western Australia to Laonice cf. weddellia.

\section{Laonice cf. quadridentata Blake \& Kudenov, 1978}

Figures 12-13

Material examined. Australia: Gulf of Carpentaria: 1558.9056' S, 13944.0076' E, 02 Mar 2005, 39.8 m, 1 specimen, QM G228999; 1559.5044' S, 139³3.4908' E, 2 Mar 2005, 42.2 m, 1 specimen, QM G229007; 1654.0' S,

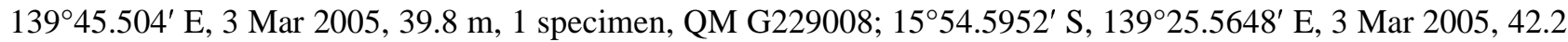
m, 1 specimen, QM G229010; 1548.5046' S, 13945.5112' E, 4 Mar 2005, 43.6 m, 1 specimen, QM G229014; $15^{\circ} 57.4908^{\prime}$ S, $139^{\circ} 36.5082^{\prime}$ E, 5 Mar 2005, 41.8 m, 1 specimen, QM G229021; 15³6.3282' S, 137 $56.607^{\prime}$ E, 7 Mar 2005, 46.0 m, 1 specimen, QM G229031; 13⒛67' S, 13650.6556' E, 11 Mar 2005, 39.2 m, 3 specimens, QM G229052; $13^{\circ} 12.4962^{\prime} \mathrm{S}, 136^{\circ} 50.4672^{\prime} \mathrm{E}, 12$ Mar 2005, $40 \mathrm{~m}, 2$ specimens, QM G229056; 15 $46.5420^{\prime} \mathrm{S}$, $138^{\circ} 14.5296^{\prime}$ E, 19 Mar 2005, 43 m, 1 specimen, QM G229099.

Additional material examined. Laonice quadridentata Blake \& Kudenov, 1978. Australia: Victoria: Port

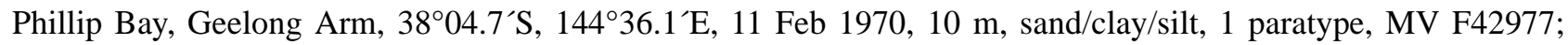

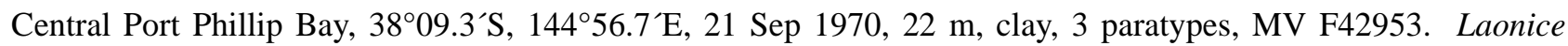
petersenae Radashevsky \& Lana, 2009. SW Atlantic Ocean, Brazil, Paraná, Paranaguá Bay: mouth of Maciel River, $25^{\circ} 33.5^{\prime} \mathrm{S}, 48^{\circ} 25.5^{`} \mathrm{~W}, 17 \mathrm{Jul} 2002,15 \mathrm{~m}, 8$ paratypes, SMF 13960.

Description (based on Gulf of Carpentaria specimens of Laonice cf. quadridentata). All anterior fragments, with 39 chaetigers maximum, specimens $0.4-1.6 \mathrm{~mm}$ wide.

Prostomium anteriorly rounded, entire, fused to peristomium at anterior margin; laterally separated from peristomium by two grooves; posteriorly with caruncle merging into middorsal ridge, extending well into mid-body region, usually until end of fragment. Distinct finger-like occipital antenna present; arising at posterior part of prostomium behind eyes. Eyes one pair of two large reddish to dark brown patches across middle of prostomium; sometimes almost touching. Peristomium dorsoanteriorly fused with prostomium, well developed, forming moderate lateral bulges. Palps lost in all specimens. Nuchal organs as double ciliary bands running along each side of caruncle and middorsal ridge; maybe U-shaped but shape and posterior extension of ciliary bands not unambiguously discernible due to moderate to poor condition of material; in one specimen ciliary bands seem to reach chaetiger 15 , in others visible to chaetiger 4,7 or 10 (Fig. 12A).

Branchiae present from chaetiger 2, usually continuing along entire fragment; first branchiae small, cirriform or minute, stump-like (particularly in specimens with body widths $<1 \mathrm{~mm}$ ), thereafter quickly increasing in length; from chaetiger 4 cirriform branchiae same length as notopodial postchaetal lamellae, longest branchiae present in mid-body region, about twice as long as notopodial postchaetal lamellae, in larger specimens at least 2.5-times length of postchaetal lamella; branchiae completely free from notopodial postchaetal lamellae.

Chaetiger 1 not reduced, with well-developed parapodia; postchaetal lamellae rounded in both rami. From chaetiger 2 notopodial postchaetal lamellae leaf-like, initially tapered, from about chaetiger 4-6 rather elongate with rounded tip; neuropodial lamellae of chaetigers 2-4 subtriangular, becoming more rounded but usually with indistinct tip in subsequent chaetigers; in chaetigers of the mid-body region neuropodial lamellae elongate, often reaching ventral side of body (Fig. 12B-E). Distinct but low prechaetal lamella present in neuro- and notopodia. Dorsal crests absent. Interparapodial pouches from chaetiger 6,8 or 13; continuing until end of fragment.

Chaetae in two rows in noto- and neuropodia of anterior and middle chaetigers; anterior row shorter and stouter than posterior row, granulated near tip; chaetae in posterior row long thin simple capillaries; in neuropodia of anterior body (first 10-15 chaetigers) number of chaetae in posterior row usually higher than in anterior row. Neuropodial hooded hooks present in few specimens only (Gulf of Carpentaria specimens are all anterior fragments only); usually starting as single hook in inferior position, hooks starting from chaetigers 26-33; two teeth above the main fang (Fig. 13B, see Remarks). Thin capillaries in addition to hooks present in superior position, 15 in number, exceeding hooks in length. Start of sabre chaetae difficult to determine (see Methods: Description of characters and procedures); in smaller specimens supposedly from about chaetiger 16, later in larger specimens. 
Pygidium unknown.

Colour. White in ethanol, usually with faint greyish or brownish pigment on parapodial postchaetal lamellae from about chaetiger 10-25; before chaetiger 10 and after chaetiger 25 very faint pigment only in notopodial lamellae.

Distribution. Australia, Gulf of Carpentaria, 39-43 m (Figs. 1-2).
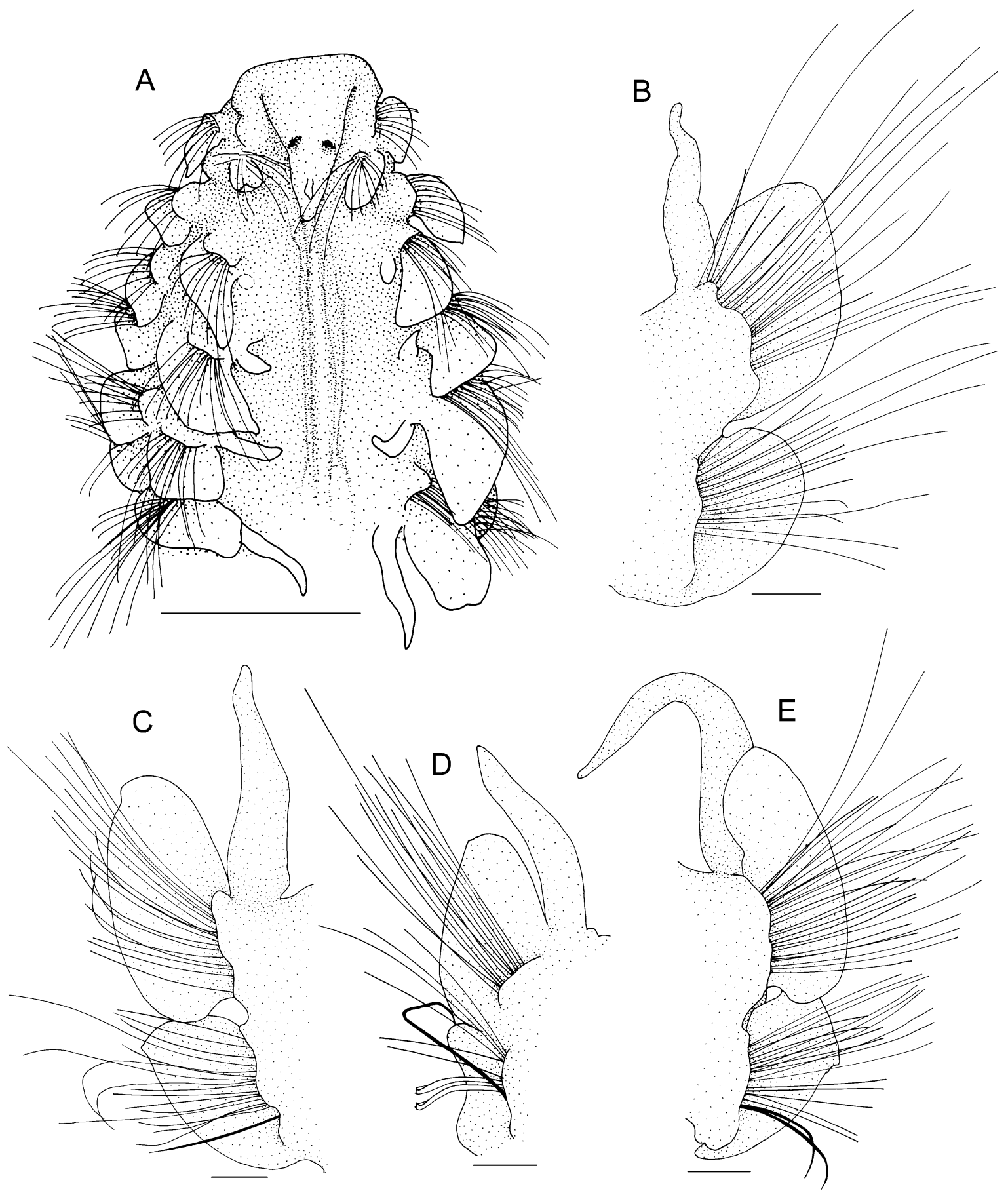

FIGURE 12. Laonice cf. quadridentata Blake \& Kudenov, 1978. A Anterior end from dorsal; back of specimen damaged after chaetiger 4 (QM G229031). B. Parapodium 5 (left) (QM G229014). C. Parapodium 16 (right) (QM G229031). D. Parapodium 35 (right) (QM G229014). E. 22 ${ }^{\text {nd }}$ parapodium (left) (QM G229031). Scales: A $0.5 \mathrm{~mm}$; B-D $0.1 \mathrm{~mm} ; \mathrm{E} 0.2 \mathrm{~mm}$. 


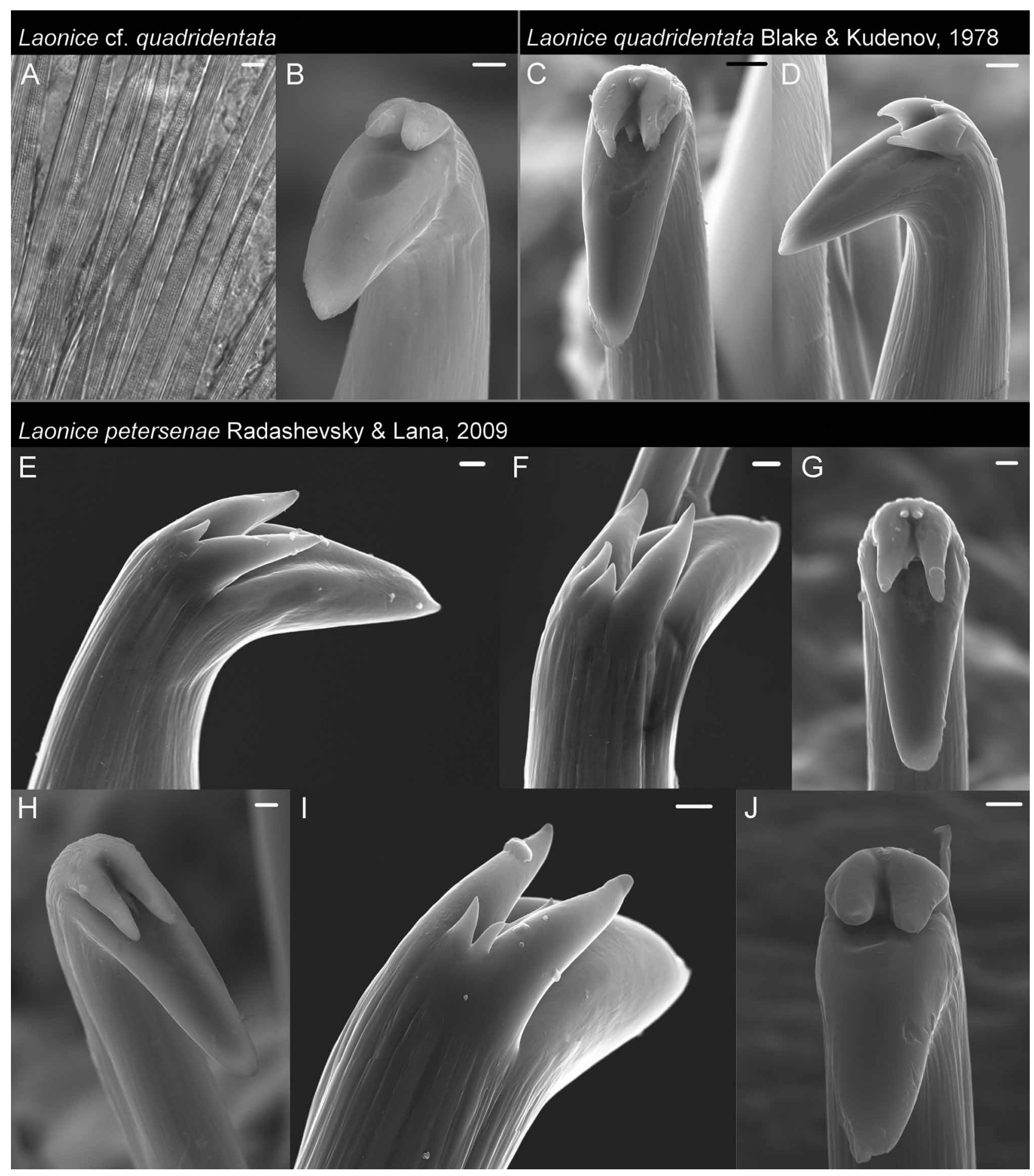

FIGURE 13. A, B Laonice cf. quadridentata. A. Notochaetae from chaetiger 5. B. Neuropodial hook from chaetiger 36, hood removed. C, D. Laonice quadridentata Blake \& Kudenov, 1978 (paratype, MV F42953): Neuropodial hooks from chaetiger 45, hoods removed. E-J Laonice petersenae Radashevsky \& Lana, 2009 (2 paratypes, SMF 13960): E-G, I neuropodial hooks from chaetiger 61, H, J same from chaetiger 55, all hoods removed. Scales: A $5 \mu \mathrm{m}$; B E-J $1 \mu \mathrm{m}$; C, D $2 \mu \mathrm{m}$.

Remarks. Laonice from the Gulf of Carpentaria were identified as $L$. cf. quadridentata based on the fusion between prostomium and peristomium, the beginning of interparapodial pouches after chaetiger 6 , and the late start of neuropodial hooded hooks, not before chaetiger 26. Laonice quadridentata was described by Blake \& Kudenov (1978), from Port Phillip Bay, Victoria, Australia. The most striking feature of L. quadridentata is the fusion of prostomium and peristomium. However, from the literature it is known that species morphologically similar to $L$. 
quadridentata show great ontogenetic and individual variability (Sikorski 2002, 2003a, Radashevsky \& Lana 2009, see Discussion). Such variability was not reported by Blake \& Kudenov (1978) in the original description of $L$. quadridentata. This lack of variation is in good agreement with the results of our examination of four paratypes of L. quadridentata, with the exception that our SEM studies of the two paratypes possessing hooks revealed that the number of apical teeth in the neuropodial hooded hooks varied between 3-4 within a single individual (Fig. 13C, D). Although our specimens of Laonice cf. quadridentata from the Gulf of Carpentaria were comprised of short anterior fragments, many in poor condition and only a few with hooks, our specimens exhibited considerable variability in regard to the extension of the nuchal organ, the beginning of interneuropodial pouches, and the start of hooded hooks in the neuropodia (see description above). Also, the start of sabre chaetae appeared to vary, though it was difficult to determine the exact position where sabre chaetae were first present (see Methods). Due to the limitations of available material, it is impossible to provide data on these characters in relation to the total number of chaetigers or to last branchiate chaetigers as did Sikorski (2002, 2003a) and Radashevsky \& Lana (2009). Based on the available material and knowledge of the importance of size-related variability in understanding species boundaries in Laonice, we have to refrain from a formal assignment to one of the currently valid species and the material from the Gulf of Carpentaria is referred to here as Laonice cf. quadridentata.

\section{Key to Australian Laonice species}

1. Neuropodial hooded hooks with 1 large main tooth and $1-4$ accessory teeth $\ldots \ldots \ldots \ldots \ldots \ldots \ldots$ Neuropodial hooded hooks with no obvious main tooth and many (5+) accessory teeth (Fig 9 A-B) . . . L. pectinata sp. nov.

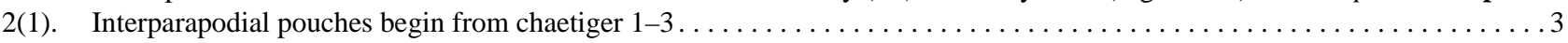

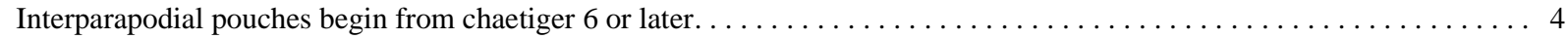

3(2). Nuchal organ extends to about chaetiger $50 \ldots \ldots \ldots \ldots \ldots \ldots \ldots \ldots \ldots \ldots \ldots \ldots \ldots \ldots \ldots \ldots$ hermaphroditica

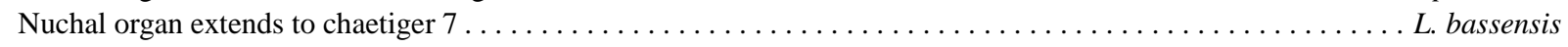

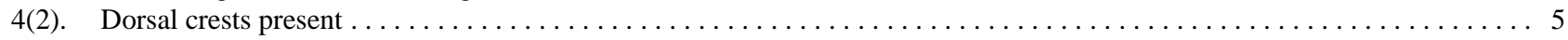

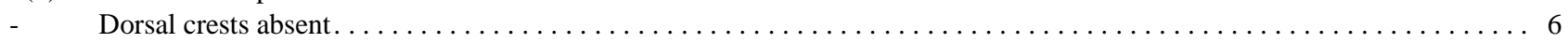

5(4). Anterior chaetiger have 5 rows of capillary chaetae.................... weddellia/L. cf. weddellia (see main text) Anterior chaetigers have 2 rows of capillary chaetae $\ldots \ldots \ldots \ldots \ldots \ldots \ldots \ldots \ldots \ldots \ldots \ldots \ldots \ldots$ Laonice lemniscata $\mathbf{s p . ~ n o v . ~}$

6(4). Occipital antenna absent; nuchal organ absent, prostomium fused with dorsum (Figs. 5A, 6A), pair of ridges arising posteriorlaterally from the prostomium (Fig. 6A), notopodial hooded hooks present from chaetiger 20-40; interparapodial pouches terminate chaetiger 10-18, some anterior pouches with additional dorsal flap (Fig. 6E) . . . . . . . . . . L. insolita sp. nov. Occipital antenna present; notopodial hooded hooks absent; interparapodial pouches terminate about chaetiger 50, prostomium and peristomium fused anteriorly $\ldots \ldots \ldots \ldots \ldots \ldots \ldots \ldots \ldots$. quadridentata/L. cf. quadridentata (see main text)

\section{Discussion}

In this paper we describe three new species of Laonice from northern and western Australia (two additional species are of uncertain identity) bringing the total to 32 recognised species of which $45 \%$ have been described in the past 10 years. The accelerated rate of species discovery is entirely due to exploration of regions that were previously poorly studied, including continental shelf and slope depths of the North Atlantic (Maciolek 2000), North Pacific (Sikorski 2003b), South America (Radashevsky \& Lana 2009) and from canyons and hydrothermal vents (Aguirrezabalaga \& Ceberio 2005; Sigvaldadottir \& Desbruyeres 2003). The same is true of this paper, which is based on the first systematic studies of benthos of the continental shelf and slope of western and northern Australia. At least seven species of Laonice are now known from Australian waters, up from three species known previously (Wilson \& McDairmid 2003). This increase is perhaps unsurprising given that previous work in Australia was based on material from the southeast (Blake \& Kudenov 1978). Nevertheless the result is consistent with that for other Spionidae and for Eulepethidae, Eunicidae, Nereididae, Phyllodocidae, Polynoidae (Wilson et al. in prep), suggesting that the species richness of polychaetes in Australian waters, estimated in 2003 at 1200 species (Wilson et al. 2003 ) is likely to be at least double that number and that existing taxonomic tools will be inadequate for identification of polychaetes for those extensive parts of the Australian continental margin that remain poorly studied.

Our consideration of the identity of Laonice cf. quadridentata from the Gulf of Carpentaria has led us to address more broadly the problem of how to differentiate Laonice species with fused prostomium and peristomium. Several such species are currently under review elsewhere (Sikorski in preparation, poster presented at 10th Inter- 
national Polychaete Conference, Lecce, Italy). However, according to Sikorski (2003a) at least the following Laonice species share this character with $L$. quadridentata: $L$. cirrata (Sars, 1851) from Hammerfest, Norway, $L$. brevicornis (Kinberg, 1866) from off Rio de Janeiro (Brazil), L. bahusiensis Söderström, 1920 from the Gullmarfjord (Sweden), L. bassensis Blake and Kudenov, 1978 from Bass Strait (Australia), L. shamrockensis Sikorski, 2003 from the Shamrock Canyon in the eastern South Atlantic Ocean, and L. petersenae Radashevsky \& Lana, 2009 from Bahia south to Paraná (Brazil). Among these species L. cirrata, L. bahusiensis and L. petersenae are known to show significant variability. Characters found to exhibit a strong relationship to size in all three species are, for example, the first presence of neuropodial hooks, the presence of branchiae along the body, the longitudinal extension of the nuchal organs, the first occurrence of sabre chaetae, and the beginning of intersegmental pouches (Radashevsky \& Lana 2009; Sikorski 2002, 2003a). In addition to the ontogenetic variability, considerable individual variability was also observed (compare data provided in Sikorski 2002 and 2003, Radashevsky \& Lana 2009).

An understanding of the ontogenetic component of morphological variability provides a basis for reassessing taxa: For example Sikorski (2002) analysed size-related variation in characters traditionally used for species separation within the genus to confirm $L$. bahusiensis, which was long regarded a junior synonym of $L$. cirrata, as a valid species (Maciolek (2000) had earlier also suggested that L. bahusiensis and L.cirrata represent separate species but without documenting morphological differences or variation). Radashevsky \& Lana (2009) in their original description of $L$. petersenae briefly discussed only $L$. cirrata as a morphologically similar species. Unfortunately they do not give information on how to distinguish the two species but emphasize that "... the variation of all three characters in $L$. petersenae sp. nov. falls within the range of the variation of these characters in $L$. cirrata..." (Radashevsky \& Lana 2009, p. 278).

Blake \& Kudenov (1978) on the other hand stated that L. quadridentata can be distinguished from L. cirrata by the quadridentate hooded hooks in the first species opposed to the bidentate hooded hooks in the latter. According to Sikorski (2003), presenting results of his SEM studies, the hooks of L. cirrata are tridentate and exceptionally with two very small extra-apical teeth. Radashevsky \& Lana (2009) stated that the hooks in L. petersenae are tridentate. Since the number of apical teeth has to be regarded as crucial for the separation of the different species based on the literature, we also did SEM studies of the hooded hooks of L. petersenae, L. quadridentata, and specimens from the Gulf of Carpentaria (Fig. $13 \mathrm{C}-\mathrm{J}$ ). We found hooks with two to five apical teeth in the paratype of L. petersenae and thus have to emend the findings by Radashevsky \& Lana (2009) (Fig. 13E-J). The presence of a pair of apical teeth above the main fang appears to be stable, but there is sometimes an additional tooth present in between the main fang and the pair of teeth, as well as up to two superior tiny teeth. In the parapodium of the examined paratype of L. quadridentata, examination with SEM shows a pair of apical teeth above the main fang is also present, as well as two additional teeth, one superior and one inferior to the pair of apical teeth (Fig. 13C). The inferior additional tooth was lacking in some hooks (Fig. 13D). Also, since only one parapodium could be examined, it cannot be excluded that the number of superior-most teeth varies as in $L$. petersenae. In the small specimens of $L$. cf. quadridentata from the Gulf of Carpentaria, no teeth in addition to the pair of apical teeth were present. It can be concluded that based on current knowledge the overall number of apical teeth cannot serve as a diagnostic character and help to separate L. petersenae and L. quadridentata. Moreover, our comparative study of the paratypes of $L$. petersenae and $L$. quadridentata did not find any morphological differentiation of the two species. They even had the same pigment pattern, and also no differences in the chaetae were found. One conclusion might be that $L$. petersenae is a junior synonym of $L$. quadridentata. Ontogenetic and individual variability known for $L$. petersenae and supposedly also present in L. quadridentata however might conceal morphological differences. It would be necessary to examine specimens of different ontogenetic stages to allow a final conclusion.

The problem, however, applies not only to L. quadridentata and L. petersenae but to all Laonice with a fused prostomium and peristomium. Laonice brevicornis is poorly known and we do not know where type material is deposited. Laonice shamrockensis was based on one specimen and the author was not completely convinced that an occipital tentacle is indeed absent in this species or was just lost from the holotype (Sikorski 2003). All diagnostic characters identified for L. bassensis are characters of high variability in the other species; the character states as described for $L$. bassensis fall into the range of other Laonice species with a fused prostomium and peristomium. So it is obvious that taxonomic problems involving these species are significant. The inclusion of genetic studies will be necessary to shed light on the identity of the species. This is also the case for the only species found in the Gulf of Carpentaria material, Laonice cf. quadridentata, which was previously known only from southern Australia, and for which questions remain as to its intraspecific variation and its similarity to other species. 


\section{Acknowledgements}

We gratefully acknowledge colleagues and crew on board FRV Southern Surveyor for long days of field work off the coast of western and northern Australia, and to Jo Browne and David Staples who sorted the samples. For providing material from their collections we thank Mal Bryant (Queensland Museum), Chris Rowley (Museum Victoria), and Dieter Fiege (Senckenberg Museum). Renate Walter and Frank Friedrich (University of Hamburg) assisted with SEM studies, while Rodrigo Bustamante (CSIRO) made available material from the Gulf of Carpentaria survey he supervised. This work has been funded through the Commonwealth Environment Research Facilities (CERF) program, an Australian Government initiative supporting world class, public good research. The CERF Marine Biodiversity Hub is a collaborative partnership between the University of Tasmania, CSIRO Wealth from Oceans Flagship, Geoscience Australia, Australian Institute of Marine Science and Museum Victoria.

\section{References}

Aguirrezabalaga, F. \& Ceberio, A. (2005) Spionidae (Annelida: Polychaeta) from the Capbreton Canyon (Bay of Biscay, NE Atlantic) with descriptions of a new genus and three new species. Marine Biology Research, 1, 267-280.

Banse, K. \& Hobson, D. (1968) Benthic polychaetes from Puget Sound, Washington, with remarks on four other species. Proceedings of the United States National Museum, 125, 1-53.

Blake, J.A. (1983) Polychaetes of the family Spionidae from South America, Antarctica, and adjacent seas and islands. Antarctic Research Series, 39, 205-287.

Blake, J.A. (1996) Family Spionidae Grube, 1850. In: J. A. Blake, B. Hilbig \& P. H. Scott (Eds), The Annelida. Part 3 Polychaeta: Orbiniidae to Cossuridae. Santa Barbara Museum of Natural History, Santa Barbara, California, pp. 81-224.

Blake, J.A. \& Kudenov, J.D. (1978) The Spionidae (Polychaeta) from southeastern Australia and adjacent areas with a revision of the genera. Memoirs of the National Museum of Victoria, 39, 171-280.

Hartman, O. (1953) Non-pelagic polychaeta of the Swedish Antarctic Expedition 1901-1903. Further Zoological Results of the Swedish Antarctic Expedition 1901-1903, 4, 1-83.

Hartman, O. (1978) Polychaeta from the Weddell Sea quadrant Antarctica. Antarctic Research Series, 26, $125-223$.

Kinberg, J.G.H. (1866) Annulata nova. Öfversikt af Kongliga Svenska Vetenskaps Akademiens Förhandlingar, 23, 97-103.

Maciolek, N.J. (2000) New species and records of Aonidella, Laonice, and Spiophanes (Polychaeta: Spionidae) from shelf and slope depths of the western North Atlantic. Bulletin of Marine Science, 67, 529-547.

Meißner, K.M. \& Hutchings, P.A. (2003) Spiophanes species (Polychaeta: Spionidae) from Eastern Australia, with a description of new species, new records and an emended generic diagnosis. Records of the Australian Museum, 55, 117-140.

Moore, J.P. (1907) Descriptions of new species of spioniform annelids. Proceedings of the Academy of Natural Sciences of Philadelphia, 59, 195-207.

Nishino, Y. \& Ohwada, T. (1991) A sonication technique to remove the hoods of hooded hooks for the SEM observation of polychaete setae. 48, 242-245.

Nonato, E.F., Bolivar, G.A. \& Lana, P.d.C. (1986) Laonice branchiata, a new species of Spionidae (Annelida; Polychaeta) from the southeastern Brazilian coast. Neritica, 1, 21-25.

Pillai, T.G. (1961) Annelida Polychaeta of Tambalagam Lake, Ceylon. Ceylon Journal of Science (Biological Sciences), 4, 164.

Poore, G.C.B., McCallum, A.W. \& Taylor, J. (2008) Decapod Crustacea of the continental margin of southwestern and central Western Australia. Museum Victoria Science Reports, 11, 1-108.

Radashevsky, V.I. \& Lana, P.C. (2009) Laonice (Annelida: Spionidae) from South and Central America. Zoosymposia, 2, 265295.

Sars, M. (1851) Beretning om en i Sommeren 1849 foretagen zoologisk Reise i Lofoten og Finmarken. Nyt Magazin for Naturvidenskaberne, 2, 121-211.

Sigvaldadóttir, E. \& Desbruyeres, D. (2003) Two new species of spionidae (Annelida : polychaeta) from Mid-Atlantic ridge hydrothermal vents. Cahiers de Biologie Marine, 44, 219-225.

Sigvaldadóttir, E., Mackie, A.S.Y. \& Pleijel, F. (1997) Generic interrelationships within the Spionidae (Annelida: Polychaeta). Zoological Journal of the Linnean Society, 119, 473-500.

Sikorski, A.V. (1997) New species of Laonice (Spionidae, Polychaeta) from the north-western Atlantic. Zoologichesky Zhurnal, 76, 501-503.

Sikorski, A.V. (2002) On distinguishing the morphologically close species, Laonice cirrata and L. bahusiensis (Polychaeta, Spionidae). Zoologicheskii Zhurnal, 81, 406-419.

Sikorski, A.V. (2003a) Laonice (Polychaeta, Spionidae) in the Arctic and the North Atlantic. Sarsia, 88, 316-345.

Sikorski, A.V. (2003b) On the fauna of the genus Laonice (Polychaeta, Spionidae) in the northern Pacific. Zoologicheskii Zhurnal, 82, 1179-1190.

Sikorski, A.V., Jirkov, I.A. \& Tsetlin, A.B. (1988) The genus Laonice (Polychaeta, Spionidae) in the Arctic Ocean - Weighing 
the Taxonomic characters and species composition. Zoologichesky Zhurnal, 67, 826-838.

Sikorski, A.V. \& Wu, B.L. (1998) A new species of Laonice (Polychaeta, Spionidae) from the Yellow Sea. Zoologicheskii Zhurnal, 77, 1242-1248.

Söderström, A. (1920) Studien über die Polychätenfamilie Spionidae. Dissertation: Uppsala University.

Ward, L.A. (1981) Spionidae (Polychaeta: Annelida) from Hawaii, with descriptions of five new species. Proceedings of the Biological Society of Washington, 94, 713-730.

Williams, A., Althaus, F., Dunstan, P.K., Poore, G.C.B., Bax, N.J., Kloser, R.J. \& McEnnulty, F.R. (2010) Scales of habitat heterogeneity and megabenthos biodiversity on an extensive Australian continental margin (100-1100 m depths). Marine Ecology, 31, 222-236.

Wilson, R.S., Hutchings, P.A. \& Glasby, C.J. (2003) Polychaetes - An interactive identification guide [CD-ROM]. Melbourne: CSIRO Publishing.

Wilson, R.S. \& McDairmid, H. (2003) Spionidae (Polychaeta)-A DELTA database of genera, and Australian species. In: R.S. Wilson, P.A. Hutchings \& C.J. Glasby (Eds), Polychaetes: An Interactive Identification Guide. CSIRO Publishing, Melbourne.

Winsnes, I.M. (1985) The use of methyl green as an aid in species discrimination in Onuphidae (Annelida, Polychaeta). Zoologica Scripta, 14, 19-23. 